\title{
Hypomethylated drm1 drm2 cmt3 mutant phenotype of Arabidopsis thaliana is related to auxin pathway impairment
}

\author{
Ivano Forgione ${ }^{\mathrm{a}, \mathrm{b}, \mathrm{c}}$, Magdalena Wołoszyńska ${ }^{\mathrm{b}, \mathrm{c}}$, Marianna Pacenza ${ }^{\mathrm{a}}$, Adriana Chiappetta ${ }^{\mathrm{a}}$, \\ Maria Greco $^{\mathrm{a}, \mathrm{d}}$, Fabrizio Araniti ${ }^{\mathrm{e}}$, Maria Rosa Abenavoli ${ }^{\mathrm{e}}$, Mieke Van Lijsebettens ${ }^{\mathrm{b}, \mathrm{c}}$, \\ Maria Beatrice Bitonti ${ }^{\mathrm{a}}$, Leonardo Bruno ${ }^{\mathrm{a}}$, \\ a Dipartimento di Biologia, Ecologia e Scienze della Terra, Università della Calabria, Arcavacata di Rende (CS), 87036 Arcavacata di Rende, CS, Italy \\ ${ }^{\mathrm{b}}$ Department of Plant Biotechnology and Bioinformatics, Ghent University, 9052 Ghent, Belgium \\ ${ }^{\mathrm{c}}$ Center Plant Systems Biology, VIB, 9052 Ghent, Belgium \\ ${ }^{\mathrm{d}}$ The Francis Crick Institute, London NW1 1AT, United Kingdom \\ e Dipartimento di Agraria, Università Mediterranea di Reggio Calabria, 89124 Reggio Calabria, Italy
}

\section{A R T I C L E I N F O}

\section{Keywords:}

Arabidopsis thaliana

Epigenetics

DNA methyltransferases

Auxin pathway

\begin{abstract}
A B S T R A C T
DNA methylation carried out by different methyltransferase classes is a relevant epigenetic modification of DNA which plays a relevant role in the development of eukaryotic organisms. Accordingly, in Arabidopsis thaliana loss of DNA methylation due to combined mutations in genes encoding for DNA methyltransferases causes several developmental abnormalities.

The present study describes novel growth disorders in the drm $1 \mathrm{drm} 2 \mathrm{cmt} 3$ triple mutant of Arabidopsis thaliana, defective both in maintenance and de novo DNA methylation, and highlights the correlation between DNA methylation and the auxin hormone pathway. By using an auxin responsive reporter gene, we discovered that auxin accumulation and distribution were affected in the mutant compared to the wild type, from embryo to adult plant stage. In addition, we demonstrated that the defective methylation status also affected the expression of genes that regulate auxin hormone pathways from synthesis to transport and signalling and a direct relationship between differentially expressed auxin-related genes and altered auxin accumulation and distribution in embryo, leaf and root was observed. Finally, we provided evidence of the direct and organ-specific modulation of auxin-related genes through the DNA methylation process.
\end{abstract}

\section{Introduction}

DNA methylation, consisting of the covalent addition of a methyl group to a cytosine residue, is one of the heritable and non-heritable genome modifications which occur beyond nucleotide sequence changes, referred as epigenome [1]. Together with other epigenetic modifications, DNA methylation contribute to chromatin remodelling processes and gene expression regulation, thus playing a relevant role in plant diversity and development [2-6].

In plants, cytosine residue methylation occurs mostly in a CG, and less frequently in a $\mathrm{CHG}$ and $\mathrm{CHH}$ sequence context $(\mathrm{H}=\mathrm{A}, \mathrm{C}$ or $\mathrm{T})$ [7-9]. The DNA methylation pattern can be maintained during meiosis thus resulting in trans-generational epigenetic inheritance $[2,5,10]$. The establishment and maintenance of the DNA methylation pattern both in plants and animals is assured by different enzymatic families and subfamilies of DNA methyltransferases whose members act on different sequence context and processes (i.e. maintenance $v s$ de novo methylation). In particular, in plants, the maintenance of DNA methylation in CpG dinucleotides is assured by the METHYLTRANSFERASE1 (MET1), a homolog of the mammalian DNA METHYLTRANSFERASE 1 (DNMT1), while the maintenance methylation of CHG is carried out by CHROMOMETHYLASE 2 and 3 (CMT2 and CMT3), which are plant specific [11-18]. Asymmetric $\mathrm{CHH}$ methylation is assured by de novo methylation performed by the CMT3 and the DOMAINS REARRANGED METHYLTRANSFERASEs (DRMs), orthologs of the mammalian Dnmt3a/b methyltransferases $[19,20]$. Moreover, DNA methylation can be actively removed by DNA demethylating enzymes (DMLs), thus contributing to methylome dynamics [21,22].

Until the last decade, most of the knowledge on cytosine methylation in plants derived from studies in the model plant Arabidopsis thaliana $[7,23]$. More recently, genome-wide sequencing technologies allowed to gain insights into DNA methylation pattern in other species,

\footnotetext{
* Corresponding author.

E-mail address: leonardo.bruno@unical.it (L. Bruno).
} 
including important cereal crops such as rice and maize and vegetables such as tomato [24-26]. In plants, DNA methylation occurs primarily on transposon repeat sequences, in all contexts, thus preventing their expression and transposition and assuring genome integrity and transcriptional homeostasis [27]. When a methylated transposon is close to or within a gene, gene expression can be affected, resulting in most cases into gene silencing [28]. In addition, DNA methylation occurs also within the coding regions of actively expressed genes and at the promoter region of some differentially regulated genes [29-31]. So far, several functions have been proposed for gene body methylation in plants but its precise functionality has not yet been defined [32-34]. Conversely, cytosine methylation at the gene promoter region, preventing the binding of transcription factors to their target sequences, represents the most clear and direct mechanism by which gene expression can be regulated by this epigenetic mechanism in both mammals and plant [35-40]. Increasing or reducing methylation at promoters results in gene silencing or activation, respectively. Therefore, proper regulation of DNA methylation pattern is crucial for plant development as well as for conferring growth plasticity to plants in response to environmental stimuli. Indeed, methylome modifications represent important and early regulatory mechanisms of plant growth, from embryogenesis to organ development, flowering and fruit ripening, as well as of plant response to different stresses [41-53]. Nevertheless, the impact of the methylome dynamics on the modulation of genetic networks and metabolic pathways underlying plant development needs to be further explored.

In this context, methylation-related mutants of Arabidopsis thaliana represent a powerful and unique tool for exploring molecular and cellular mechanisms that operate in and are modulated by DNA methylation. Among these mutants, the most widely investigated is the met1; loss-of-function met1 mutants and antisense-MET1 transgenic plants exhibit a reduction in global cytosine methylation levels, particularly at CG sites [11,54]. In antisense-MET1 plants reduced DNA methylation is associated with developmental abnormalities such as reduced height, smaller rounded leaves, leaves with curled margins, decreased fertility, reduced apical dominance and shorter roots [11]. The $\mathrm{drm}_{s}$ and $\mathrm{cmt}_{s}$ single mutants as well as drm1 drm2 double homozygotes do not show any apparent alteration in phenotype, even after five generations of inbreeding $[17,55]$. However, identical pleiotropic defects are observable in the drm $1 \mathrm{drm} 2 \mathrm{cmt} 3.7$ and drm $1 \mathrm{drm} 2 \mathrm{cmt} 3.11$ (in this study we refer as $d d c$ ) triple mutants, previously characterized and representative of multiple independent lines in Landsberg erecta (Ler) and Columbia (Col-0) background, respectively [17,55,56]. In particular, both these mutants, which only differ in the $c m t 3$ allele, show a twisted leaf shape, shorter height and partial sterility, suggesting a key role of the DNA methylation status in controlling plant growth [56]. At the moment, other mutant alleles are not available for the $d d c$ mutant both in Ler and Col-0 background. Furthermore, pleiotropic effects were reversed when drm $1 \mathrm{drm} 2 \mathrm{cmt} 3$ (Ler) plants were transformed with DRM2 or CMT3, by Agrobacterium [56] confirming a compensatory mechanism between the different methyltransferases [55]. On this basis, to reveal possible biological functions of the DNA methylation at both CHG and CHH context, we focused on the ddc triple Col-0 mutant which combines defects in both maintenance and de novo DNA methylation. To this aim, we explored the developmental phenotypes and the molecular pathways affected by hypomethylation at $\mathrm{CHG}$ and $\mathrm{CHH}$ context. In particular, we focused on the auxin pathways since there are increasing evidences that link multiple epigenetic factors to hormone and, more specifically, to auxin action [57-61]. Accordingly, in the abnormal embryo of the met1 mutant both auxin distribution and the expression of the PIN1 gene, which encodes an auxin efflux carrier very important at the early stage of embryo development, were found to be impaired [57]. However, no direct impact of MET1 at the PIN1 gene locus was observed, highlighting the complexity of interaction between epigenetic regulation and hormone action and the need for further investigation [57]. In the present study, we demonstrated that from embryogenesis to post-embryonic development auxin-related pathways are targets of the combined action of DRM1, DRM2 and CMT3 which work in an organ-specific manner.

\section{Materials and methods}

\subsection{Plant lines}

Wild type line of Arabidopsis thaliana (L.) Heynh. ecotype Columbia (Col-0), as control, and the drm1 drm2 cmt3.11 (ddc) triple DNA methylation mutant of $A$. thaliana in Col-0 background were used. A. thaliana $d d c$ mutant combines $d r m 1$ (SALK_021316) with T-DNA insertion in the sixth exon, drm2 (SALK_150863) with T-DNA insertion in the last exon, and cmt3.11 (SALK_148381) with T-DNA insertion in the eighth intron [62]. Seeds of the $d d c$ mutant were purchased from the Nottingham Arabidopsis Stock Centre (NASC).

Homozygous individuals were identified through PCR genotyping by using right $[\mathrm{RP}]$ and left primers [LP] complementary to the region flanking the T-DNA insertions site in each gene and a primer (LBb1.3) complementary to the T-DNA sequence (Supplemental Fig. 1, Supplemental Tab. 1). For DRM1 and DRM2 genes a single PCR product was obtained only by the amplification with RP and LBb1.3 primers confirming the presence of the T-DNA insertion in the sixth and tenth exon, respectively (Supplemental Fig. 1). In $c m t 3$ two single PCR fragments were detected by using both pairs of primers combinations: LP with LBb1.3 and RP with LBb1.3 (Supplemental Fig. 1). This result, beside confirming T-DNA insertion in the eighth intron, is likely due to the presence of an inverted repeat of the T-DNA generated by the replication machinery during the integration process.

\subsection{Growth condition}

Seeds of both Col-0 and $d d c$ lines were surface sterilized and grown as reported in Bruno et al [63]. Briefly, the seeds were incubated in absolute ethanol for $2 \mathrm{~min}$, then in $1.75 \%$ hypochlorite solution ( $\mathrm{NaClO}$ ) for $12 \mathrm{~min}$. After thorough washing with sterile distilled water ( $5 \times 5 \mathrm{~min}$ ), the seeds were sown on either Petri dishes or square plates containing half-strength MS medium [64], 1\% sucrose and stratified at $4^{\circ} \mathrm{C}$ for $48 \mathrm{~h}$. The plated seeds were then exposed at $21^{\circ} \mathrm{C}$ under long day condition (i.e. $16 \mathrm{~h}$ white light $100 \mu \mathrm{mol} \mathrm{m}^{-2} \mathrm{~s}^{-1}$ and $8 \mathrm{~h}$ dark) and $60 \%$ relative humidity to induce germination and allow seedling growth. An additional lot of seeds was germinated on soil in pots at the same growth conditions. For the analysis of root growth plated seeds were instead exposed to continuous light condition and $60 \%$ relative humidity according to Karampelias et al. [65].

\subsection{Phenotype characterization}

For root analysis, seedlings of both Col- 0 and $d d c$ lines were grown in square plates in vertical position at the conditions above described. Primary root length was monitored up to 12 days after germination by using Image J 1.45 software. Secondary root density (= number of secondary roots $\mathrm{x} \mathrm{cm}$ of primary root length) was evaluated at 12 days after germination under a stereomicroscope. For meristem size analysis, 12 day-old seedlings were processed as described in Bruno et al. [66] and the distance and the number of cortex cells in a row extending from the QC to the first elongated cortex cell were measured [67]. Three independent replicates $(n=15$ seedlings $x$ each sample $x$ each replicate) were performed; statistical analysis of the mean, standard deviation and Student's $t$-test were applied.

Analysis of root gravitropic growth was performed on 6 day-old seedlings and the following parameters were measured as described in Grabov et al. [68]: root deviation angle ( $\beta$ ), horizontal growth index (HGI), vertical growth index (VGI) and straightness. Three independent biological replicates ( $\mathrm{n}=50$ roots $\mathrm{x}$ each sample $\mathrm{x}$ each replicate) were performed; Student's $t$-test was applied for statistical analysis. In 
addition, Lugol staining was applied to visualize starch accumulation in the amyloplast present in the columella cells of the root cap. To this aim seedling roots were incubated in Lugol solution for $5 \mathrm{~min}$, washed in water and mounted onto microscopic slides using clearing buffer (chloral hydrate: glycerol: water in 8:3:1 ratio) as the mounting medium. The seedlings roots were imaged using a DIC optic on a Leica inverted TCS SP8 (Leica Microsystems, Heidelberg, Germany) confocal scanning laser microscope with a 40x oil immersion objective. At least 15 roots were analysed for each sample.

Rosette area and leaf series analyses were performed on 21 days seedlings grown on Petri dishes at the conditions previously described. Leaves were dissected under a stereomicroscope, placed in square plates on $1 \%$ plant tissue agar, and then photographed. Rosette and single leaf area were measured by ImageJ 1.45 program. Three independent biological replicates $(n=15$ seedlings $\mathrm{x}$ each sample $\mathrm{x}$ each replicate) were performed; statistical analysis of the mean, standard deviation and Student's $t$-test were applied.

Leaf differentiation pattern was also taken into account by analysing epidermal cell features and xylem vein pattern. Epidermal cell analysis was performed on the rosette 4th leaf of 21 day-old seedlings of both Col-0 and $d d c$ lines, grown on Petri dishes as previously described. Excised leaves were clarified with $100 \%$ ethanol overnight at room temperature, then fixed in $90 \%$ lactic acid and mounted on a microscope slide. The epidermal pavement cells and stomata of the leaf adaxial side were drawn with a "Leica DMLB microscope" equipped with a drawing tube and differential interference contrast objectives (Supplemental Fig. 2). The cell area was measured with Image J 1.45 software. Number of pavement cells per leaf, epidermal cell density (= pavement cell number $\mathrm{x} \mathrm{mm^{2 }}$ ), stomatal density ( $=$ stomata number $\mathrm{x}$ $\left.\mathrm{mm}^{2}\right)$, stomatal index (= stomatal density/stomatal density + epidermal pavement cell density) were calculated [69]. Three independent biological replicates $(n=15$ seedlings $\mathrm{x}$ each sample $\mathrm{x}$ each replicate) were performed; Student's $t$-test was applied for statistical analysis.

To visualize xylem patterns, $3^{\text {rd }}$ and $4^{\text {th }}$ leaves were cleared as above described and viewed under darkfield illumination with a stereomicroscope (Leica IC80 HD). Images were captured with a digital camera. At least 20 leaves were analysed for each biological replicate $(\mathrm{n}=3)$ for both $d d c$ and Col-0 lines.

For embryo analysis immature and mature seeds from siliques of ddc mutant and Col-0 were cleared in chloral hydrate solution $(4 \mathrm{~g}$ chloral hydrate, $1 \mathrm{ml}$ glycerol, and $2 \mathrm{ml}$ water) and the embryos were observed using a DIC optic on a Leica inverted TCS SP8 confocal scanning laser microscope with a 40x oil immersion objective. At least 10 siliques at different developmental stage were used for each biological replicate $(\mathrm{n}=3)$ for both $d d c$ and Col-0 lines.

\subsection{Auxin perception and PIN localization analysis}

To analyse the auxin maxima, the proDR5::GFP auxin inducible reporter gene, which provides indication of auxin perception, was introgressed in $d d c$ through crosses with proDR5::GFP Col-0 line, kindly provided by Robert L. Fisher. Third-generation seeds from two independent homozygous mutant lines, which exhibited the same phenotype of the parental $d d c$, were used. Homozygous lines were selected by polymerase chain reaction (PCR) using T-DNA- and gene-specific primer sets as described above. For embryo analysis, seeds of $d d c \mathrm{X}$ proDR5::GFP and proDR5::GFP Col-0 were excised from green siliques at different time points after fertilization from soil-grown plants. Six and 12 day-old seedlings and rosette $4^{\text {th }}$ leaves, excised from 12 day-old seedlings grown on Petri dishes as previously described, were also sampled.

To analyse PIN distribution pPIN1::PIN1-GFP [70] and pPIN7::PIN7$G F P$ [71] reporter genes were introgressed in $d d c$ through crosses with pPIN7::PIN7-GFP and pPIN1::PIN1-GFP Col-0 lines respectively. Thirdgeneration seeds from two independent homozygous mutant lines, which exhibited the same phenotype of the parental $d d c$, were used. For primary root analysis, seeds of $d d c \mathrm{X}$ pPIN1::PIN1-GFP, pPIN1::PIN1GFP Col-0, ddc X pPIN7::PIN7:GFP and pPIN7::PIN7:GFP Col-0 were used. 8 day-old seedlings were analyzed.

Samples were fixed in paraformaldehyde $4 \%$ for $5 \mathrm{~min}$ and then transferred onto microscope slides and covered with PBS 1x buffer ( $\mathrm{NaCl} 137 \mathrm{mM}, \mathrm{KCl}_{2}, 7 \mathrm{mM}, \mathrm{Na}_{2} \mathrm{HPO}_{4} 10 \mathrm{mM}, \mathrm{KH}_{2} \mathrm{PO}_{4} 1.8 \mathrm{mM}, \mathrm{pH} 7,4$ ) and glycerol 1:1. Samples were imaged using a Leica inverted TCS SP8 confocal scanning laser microscope with a 40x oil immersion objective. The detection of Green Fluorescence Protein (excitation peak centered at about $488 \mathrm{~nm}$, emission peak wavelength of $509 \mathrm{~nm}$ ) was performed by combining the settings indicated in the sequential scanning facility of the microscope. Three independent replicates were performed and at least 30 seedlings and 60 embryos were analysed.

\subsection{Auxin quantification}

Auxin quantification was performed on rosette $4^{\text {th }}$ leaves of 13 dayold seedlings of both Col-0 and $d d c$ lines, grown on Petri dishes as previously described. Excised leaves were pooled, deep-frozen in liquid nitrogen, and powdered. For each replicate, $0.1 \mathrm{~g}$ ( $\pm 0.002 \mathrm{~g}$ ) was used and extraction and derivatization were carried out as described by Villas-Bôas et al. [72], with some modification.

Each sample was transferred in a $2 \mathrm{ml}$ centrifuge tube and $200 \mu \mathrm{l}$ of $\mathrm{NaOH}(1 \% \mathrm{w} / \mathrm{v}), 147 \mu \mathrm{l}$ of $\mathrm{MeOH}$ and $34 \mu \mathrm{l}$ of pyridine were added and the samples were vortexed for $50 \mathrm{~s}$. The extracted samples added with $20 \mu \mathrm{l}$ of methyl chloroformate were newly vortexed for $30 \mathrm{~s} \times 2$ times. Subsequently, $400 \mu \mathrm{l}$ of chloroform were added and samples were shaken for $20 \mathrm{~s}$. Finally, $400 \mu \mathrm{l}$ of a $\mathrm{NaHCO}_{3}$ solution $(50 \mathrm{mM})$ were added, samples were shaken for $20 \mathrm{~s}$ and immediately centrifuged (14.000 rpm) for $1 \mathrm{~min}$ at room temperature.

The organic fraction was collected, dispensed in new $2 \mathrm{ml}$ centrifuge tubes and the aqueous residues were eliminated using anhydrous $\mathrm{Na}_{2} \mathrm{SO}_{4}$. One hundred $\mu \mathrm{l}$ of the solution were used for the Gas chromatography-mass spectrometry (GC-MS) analysis. Indole acetic acid (IAA) relative quantification was carried out using indole propionic acid $[20 \mu \mathrm{l}(20 \mathrm{mg} / \mathrm{ml})$ for each sample] as internal standard added at the beginning of sample extraction.

GC-MS analysis was carried out as previously described by Rawlinson et al. [73] using a gas chromatograph apparatus (Trace 1310, Thermo Fisher Scientific, Waltham, MA-USA) equipped with a single quadrupole mass spectrometer (ISQ LT). The capillary column was a TG-5MS $30 \mathrm{~m} \times 0.25 \mathrm{~mm} \times 0.25 \mu \mathrm{m}$ and the gas carrier was helium with a flow rate of $1 \mathrm{ml} / \mathrm{min}$. Injector and transfer line were settled at $250^{\circ} \mathrm{C}$ and $270^{\circ} \mathrm{C}$, respectively. Three microliters of sample were injected with a 35 psi pressure pulse, which was held for $1 \mathrm{~min}$. The following temperature was programmed: isocratic for $1 \mathrm{~min}$ at $40^{\circ} \mathrm{C}$, from $40^{\circ} \mathrm{C}$ to $320^{\circ} \mathrm{C}$ with a rate of $20^{\circ} \mathrm{C} \times$ min, then isocratic for $2 \mathrm{~min}$ at $320^{\circ} \mathrm{C}$. The ion source was settled at $200^{\circ} \mathrm{C}$ and the solvent delay was $4.5 \mathrm{~min}$. Mass spectra were recorded in electronic impact (EI) mode at $70 \mathrm{eV}$, scanning at $50-400 \mathrm{~m} / \mathrm{z}$ range for selection of appropriate EI mass fragments for each sample. Then the MS was run in selected ion monitoring (SIM) using 1 quantifier ion $(\mathrm{m} / \mathrm{z}$ ) and two qualifier $(\mathrm{m} / \mathrm{z})$ for each molecule. In particular, 3-Indole acetic acid Me ester was identified using the 189, 103 and 77 ions. Compound identification was carried out comparing the relative retention time and mass spectra of molecules with pure standards derivatized as previously described and with the help of commercial libraries (NIST 2005, Wiley 7.0 etc.). Data were then expressed as percentage compared to control.

\subsection{RT-qPCR analysis}

Analysis of DRM1, DRM2, CMT3 expression in wild type plants was carried out separately on the different organs collected as detailed in the description of results. Analysis of DRM1, DRM2, CMT3 expression in $d d c$ mutant was carried out on 12 day-old whole seedlings. Analysis of 
DRMI
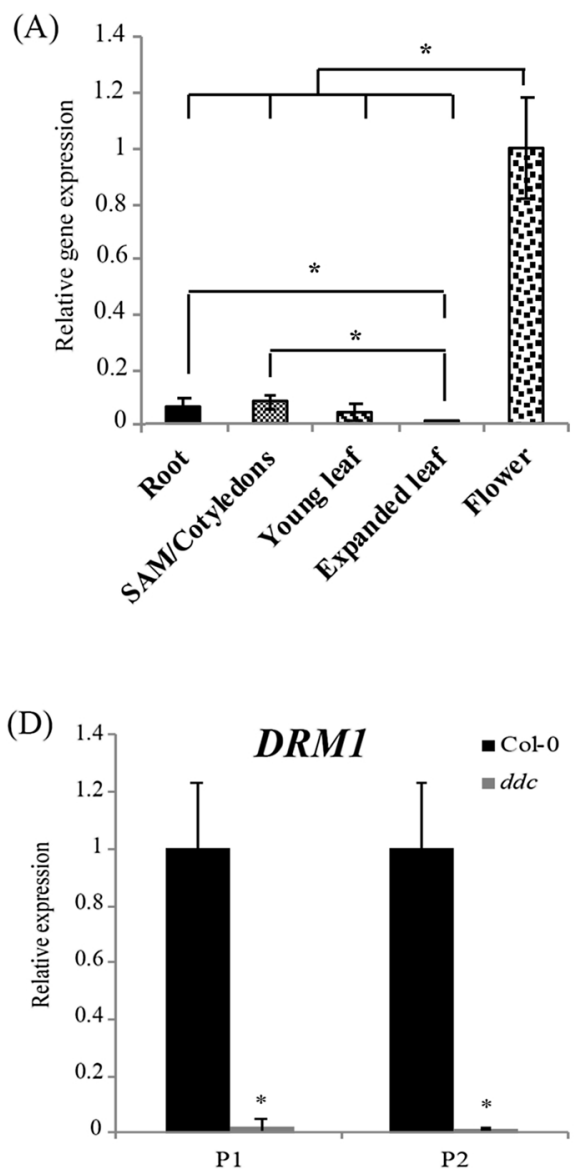

DRM2

(B)

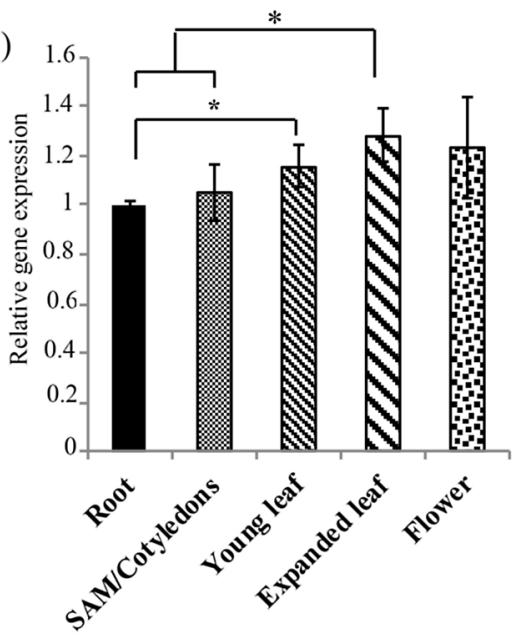

(E)

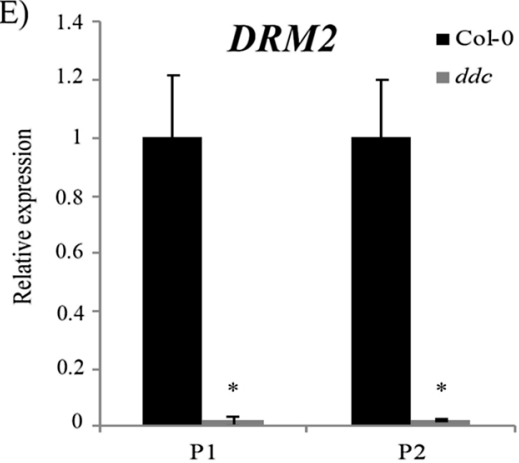

CMT3
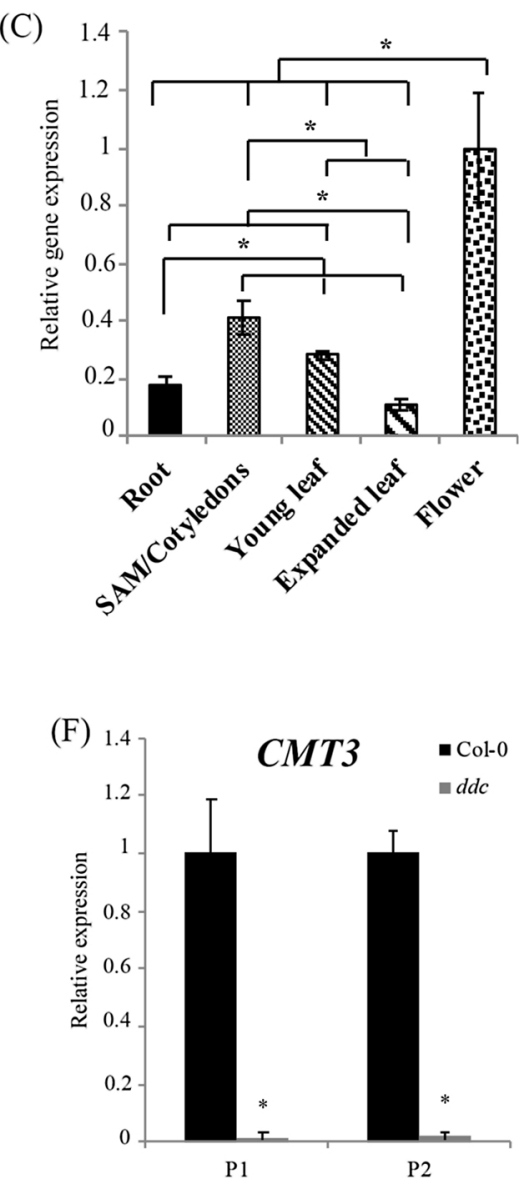

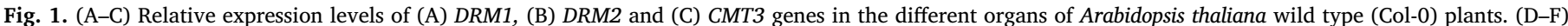

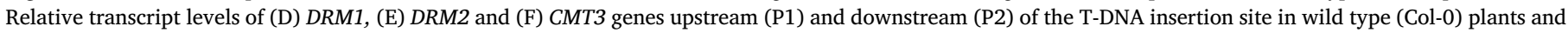

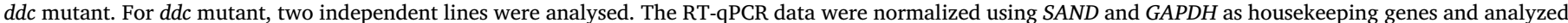

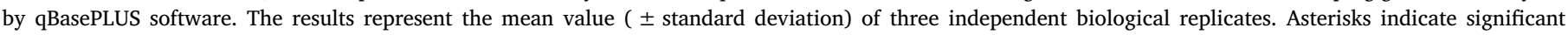
pairwise differences using Student's $t$-test ( $\mathrm{p} \leq 0.05$ ).

the expression of auxin-related genes was separately performed on leaves $\left(3^{\text {rd }}\right.$ and $\left.4^{\text {th }}\right)$ of 13 day-old seedlings and on roots of 6 and 13 day-old seedlings of both $d d c$ and Col-0 lines, grown in vitro and on soil as previously described. RNA was isolated from $100 \mathrm{mg}$ of plant tissue with the RNeasy Plant Kit (Qiagen, Hilden, Germany) with on-column DNase digestion. The manufacturer's protocol was modified by two additional washes of RNeasy spin columns with the RPE buffer. RNA quality was checked by agarose gel electrophoresis and quantified by spectrophotometry (NanoDrop technologies). Total RNA $(2,5 \mu \mathrm{g})$ was used for cDNA synthesis with SuperScript III First-strand synthesis kit (Life-Invitrogen, CAT. 18,080,051). The reaction mixes were prepared in three technical replicates by JANUS Automated Workstation (Perkin Elmer) in 384-well plates with $2.5 \mu$ Power SYBR ${ }^{\circledR}$ Green PCR Master Mix (Roche), $0.5 \mu \mathrm{l}$ of cDNA and $1 \mu \mathrm{l}$ each primer $(0.5 \mu \mathrm{M}$ final concentration). The LightCycler 480 Real-Time PCR System was used for amplification $\left(95^{\circ} \mathrm{C}\right.$ for $10 \mathrm{~min}, 40$ cycles of $95^{\circ} \mathrm{C} / 10 \mathrm{~s}, 60{ }^{\circ} \mathrm{C} / 15 \mathrm{~s}$, $72{ }^{\circ} \mathrm{C} / 30 \mathrm{~s}$, followed by melting curve analysis). The expression levels were normalized using SAND (At2g28390) and GAPDH (At1g13440) as the reference genes. The sequences of primers used are reported in Table S2-S4. The results of three independent biological replicates and three technical replicates, were analysed using the qBase PLUS software [74] and represent the mean value ( \pm standard deviation). Asterisks indicate significant pairwise differences using Student's $t$-test $(* P<$ 0.05).

\subsection{MeDIP-qPCR analysis}

Methylated DNA Immunoprecipitation (MeDIP-qPCR) was performed following the optimized protocol of [75] Weber and Schubeler (2007). Leaves ( $3^{\text {rd }}$ and $4^{\text {th }}$ ) of 13 day-old seedlings of both $d d c$ and Col0 lines, grown in soil as previously described, were excised, pooled, frozen in liquid nitrogen and ground by using mortar and pestle. About $100 \mathrm{mg}$ of tissue powder were suspended in lysis buffer, lysed in $55^{\circ} \mathrm{C}$ and used for a phenol-chloroform (2:1) extraction, DNA was precipitated with ethanol, pelleted and resuspended in buffer supplemented with RNaseA $(20 \mu \mathrm{g} / \mathrm{ml})$. The isolated DNA was sonicated in SONICS Vibra-cell sonicator with four $15 \mathrm{~s}$ pulses at $20 \%$ amplitude. Sonicated DNA was precipitated with ethanol and $4 \mu \mathrm{g}$ was used for further steps. The $5 \%$ of the volume was taken as the input sample and the rest was divided into two equal samples of mock and immunoprecipitation sample to be incubated with anti-5methylcytosine antibody (\#BI-MECY 1000 Eurogentec, Seraing, Belgium, $1 \mathrm{mg} / \mathrm{ml}$ ). Optimal antibody concentration to be used was defined by performing a preliminary assay on HEI1O gene (Fig. 10A), which was also used in MeDIP analysis as positive control of methylation decrease in $d d c \mathrm{mu}$ tant. Based on the results of this preliminary test, all the subsequent immunoprecipitation samples were incubated with $2 \mu \mathrm{l}$ of anti-5methylcytosine antibody (\#BI-MECY 1000 Eurogentec) at the final concentration of $4 \mu \mathrm{g} / \mathrm{ml}$. Dynabeads (M-280 Sheep anti-mouse IgG - Dynal 
(A)

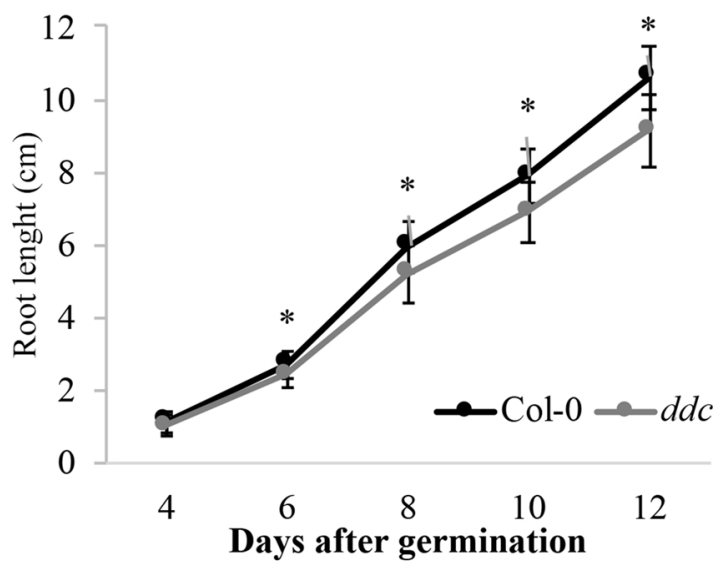

(C)

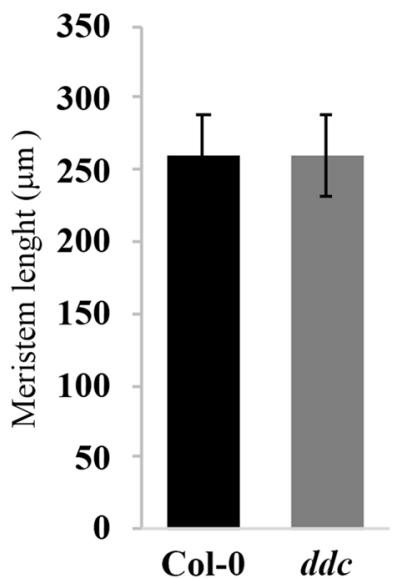

(B)

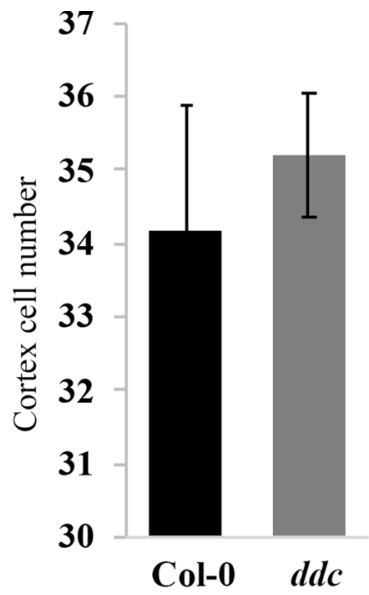

(D)

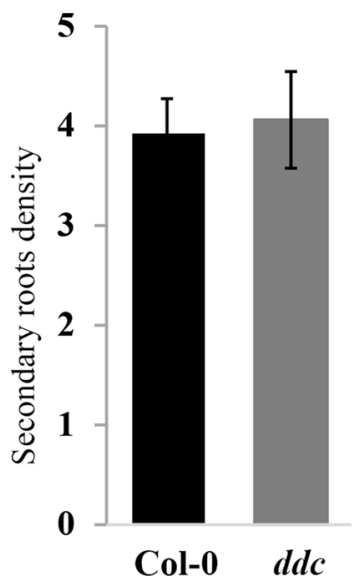

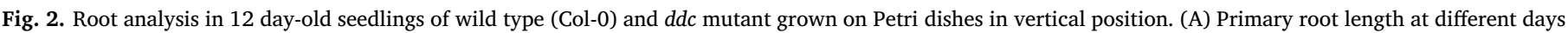

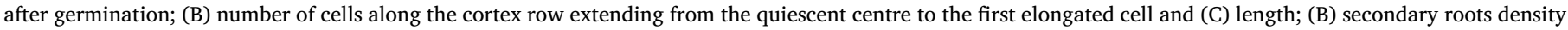

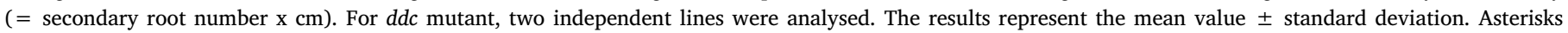
indicate significant pairwise differences using Student's $t$-test $(\mathrm{p} \leq 0.05)$.

Biotech \#112.01) were used to collect immunoprecipitated DNA. After the proteinase $\mathrm{K}$ digestion, a phenol-chloroform purification and an ethanol precipitation, the concentration of each MeDIP sample was measured by Qubit ${ }^{\circledast} 2.0$ Fluorometer Invitrogen. Mock samples were also used to check any unspecific binding of DNA to the beads. Half $\mu 1$ of each sample were analysed by real-time PCR (Roche LC480, Mannheim, Germany) with primers in the promoter and coding regions of the analysed genes to compare the amount of immunoprecipitated DNA fragments (methylated) in $d d c$ vs Col-0 samples after normalization versus input (Table S4). To account for differences in DNA concentration all the samples were normalized to ACTIN7 reference gene. The results of three independent biological replicates and three technical replicates, were analysed using the qBase PLUS software [74] and represent the mean value ( \pm standard deviation). Asterisks indicate significant pairwise differences using Student's $t$-test $(* \mathrm{P}<0.05)$.

\section{Results}

3.1. DRM1, DRM2 and CMT3 gene expression in wild type and ddc mutant lines

To obtain insight into the role of DRM1, DRM2 and CMT3 in plant development, their expression was analysed in the different organs of Arabidopsis thaliana wild type plants (Col-0) by RT-qPCR. In particular, gene expression was evaluated in cotyledons and shoot apical meristem (SAM/Cotyledons) from one week-old seedlings, first and second leaves and primary roots from two week-old seedlings, mature leaves from three week-old seedlings and opened flowers from adult plants (Fig. 1A-C). Data analysis revealed that transcript levels of DRM1 (Fig. 1A) and CMT3 (Fig. 1C) were very high in flower, much lower in root, SAM, young leaves and extremely low in expanded leaves. By contrast, DRM2 expression was constitutive in the different organs and stages in plant development (Fig. 1B).

Next, we analysed the DRM1, DRM2 and CMT3 expression in three week-old seedlings of the $A$. thaliana $d d c$ mutant line, by RT-qPCR, using two pairs of primers for each gene complementary to regions located upstream and downstream of the T-DNA insertion (Supplemental Fig. 1, Supplemental Tab. 2). No signal of partial transcripts downstream of the T-DNA insertion were detected for DRM1, DRM2 and CMT3 indicating that in the $d d c$ mutant, the DRM1, DRM2 and CMT3 genes are knocked-out (Fig. 1D-F).

\subsection{Auxin-defective phenotypes in the ddc mutant}

Subsequently, morphological phenotypes and growth parameters were accurately analysed in the $d d c$ mutant. The primary root length, monitored in seedlings grown in vertical position from 4 to 12 days after germination, was reduced in $d d c$ as compared to Col-0 plants 


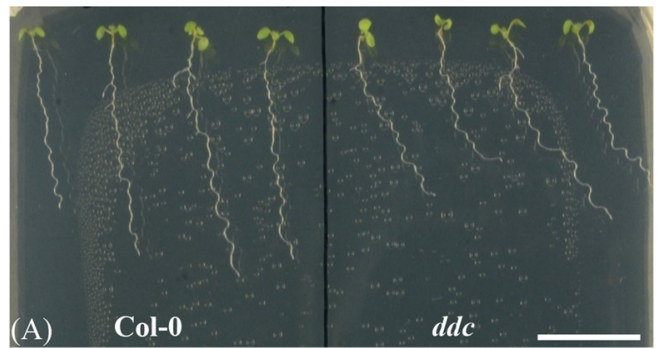

(C)

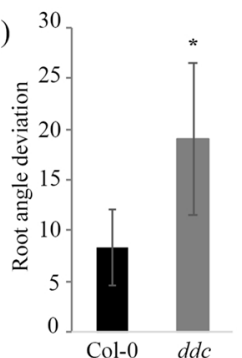

(B)

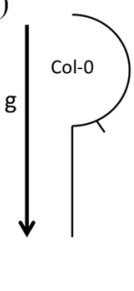

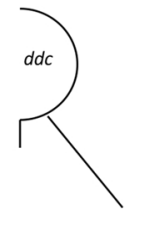

Col-0

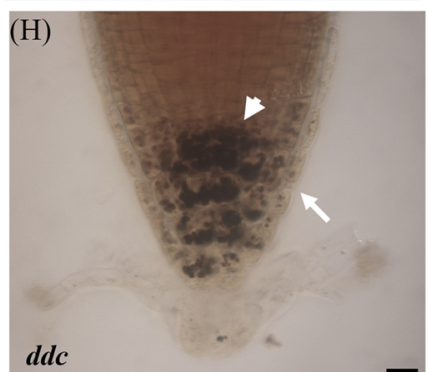

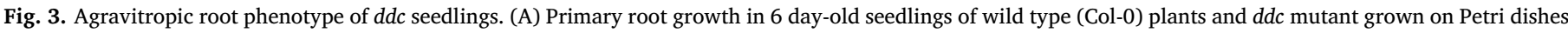

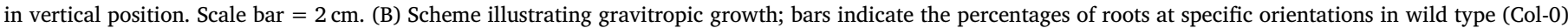

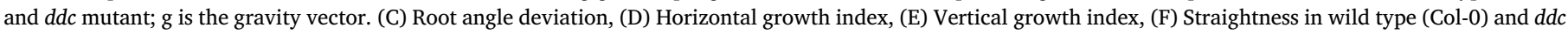

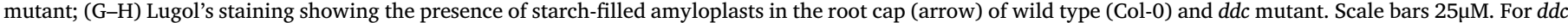

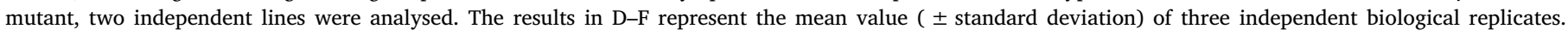
Asterisks indicate significant pairwise differences using Student's $t$-test $(p \leq 0.05)$.

(A) 4000

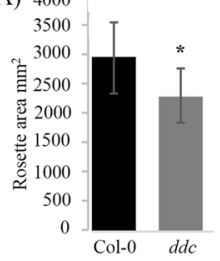

(B)

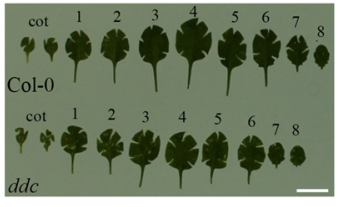

(C)

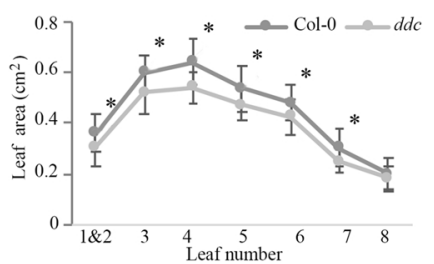

(D) 0.0022

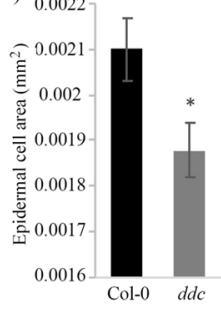

(E) 32000

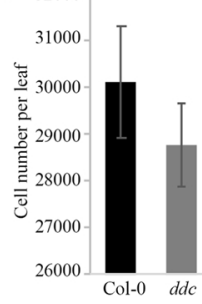

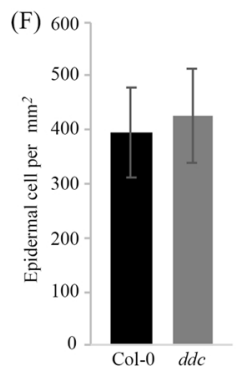
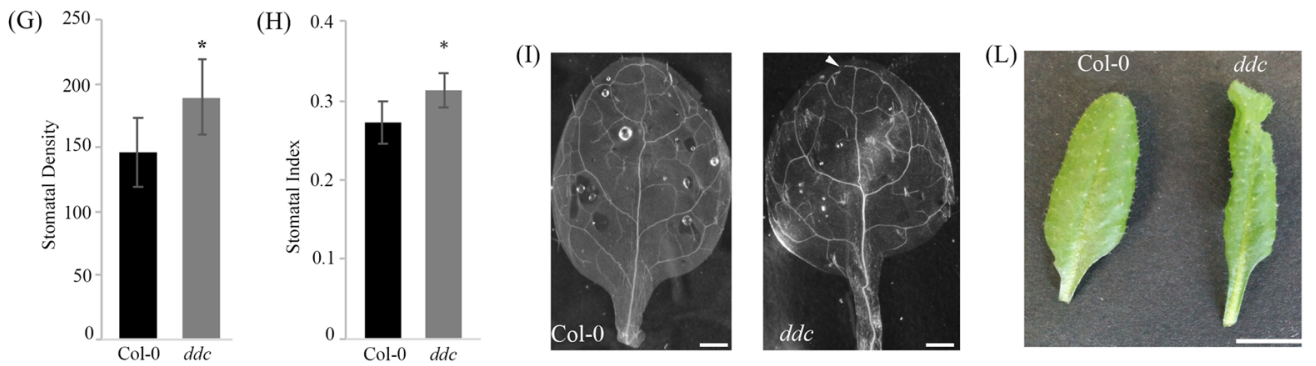

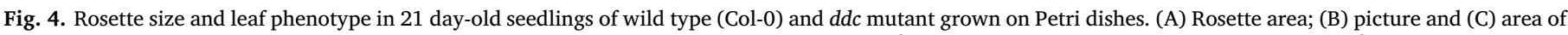

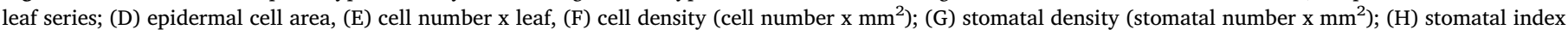

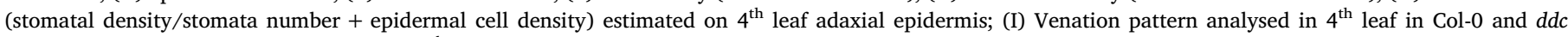

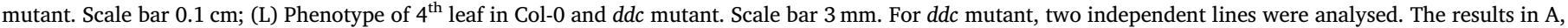
$\mathrm{C}-\mathrm{H}$ represent the mean value ( \pm standard deviation) Asterisks indicate significant pairwise differences using Student's $t$-test ( $\mathrm{p} \leq 0.05$ ).

(Fig. 2A). However, the primary root meristem size, measured as the length (Fig. 2C) and the number of cortex cells (Fig. 2B) in a row extending from the quiescent centre to the first elongated cell [76], was not significantly affected in the $d d c$ mutant as observed in 12 day-old seedlings. Also, lateral root density, defined as the number of lateral roots per primary root length unit $(\mathrm{cm})$, was comparable between the $d d c$ mutant $v s$ Col-0 (Fig. 2D).

A very intriguing feature of the $d d c$ primary root was the occurrence of an agravitropic growth behaviour (Fig. 3A and B) which, according to Grabov et al. [68], was quantified as an increased root deviation angle and horizontal growth index (HGI) and a reduced straightness and vertical growth index (VGI) (Fig. 3C-F). Interestingly, the agravitropic growth of $d d c$ mutant primary root was associated with a reduced presence of statoliths (i.e. dense amyloplasts) which usually differentiate within columella cells of root calyptra and are involved in gravity perception [77]. Indeed, following Lugol's staining which allows to highlight the presence in the cell of such starch-filled organelles, a reduced staining was observed in the root calyptra of $d d c$ mutant (Fig. 3H) compared to Col-0 (Fig. 3G).

The reduced growth capacity of the $d d c$ mutant was also apparent 

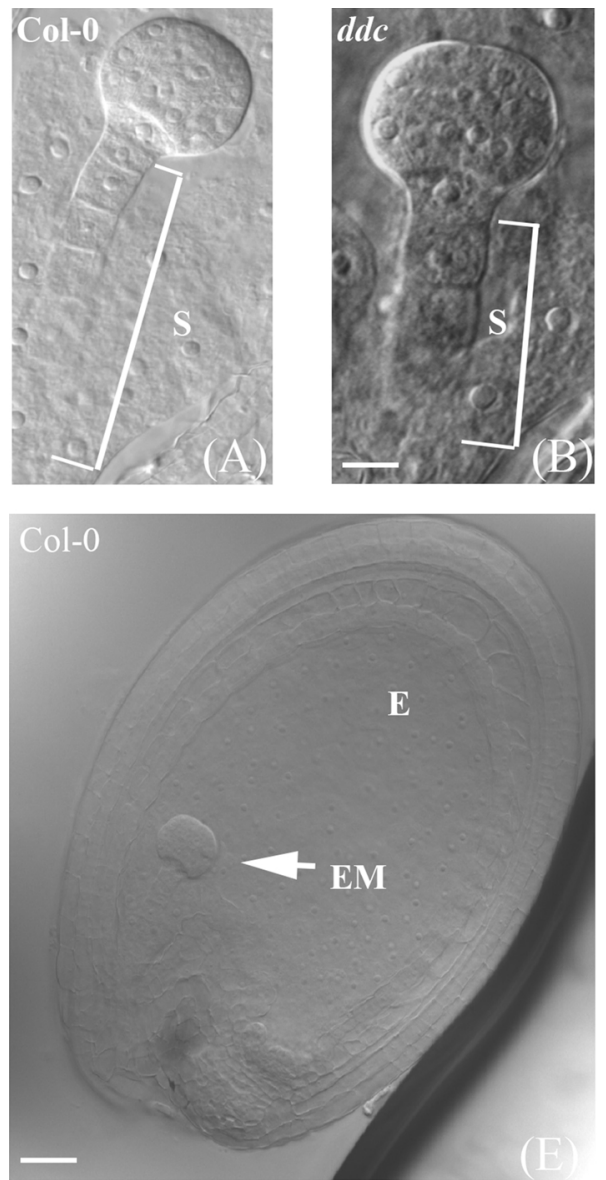
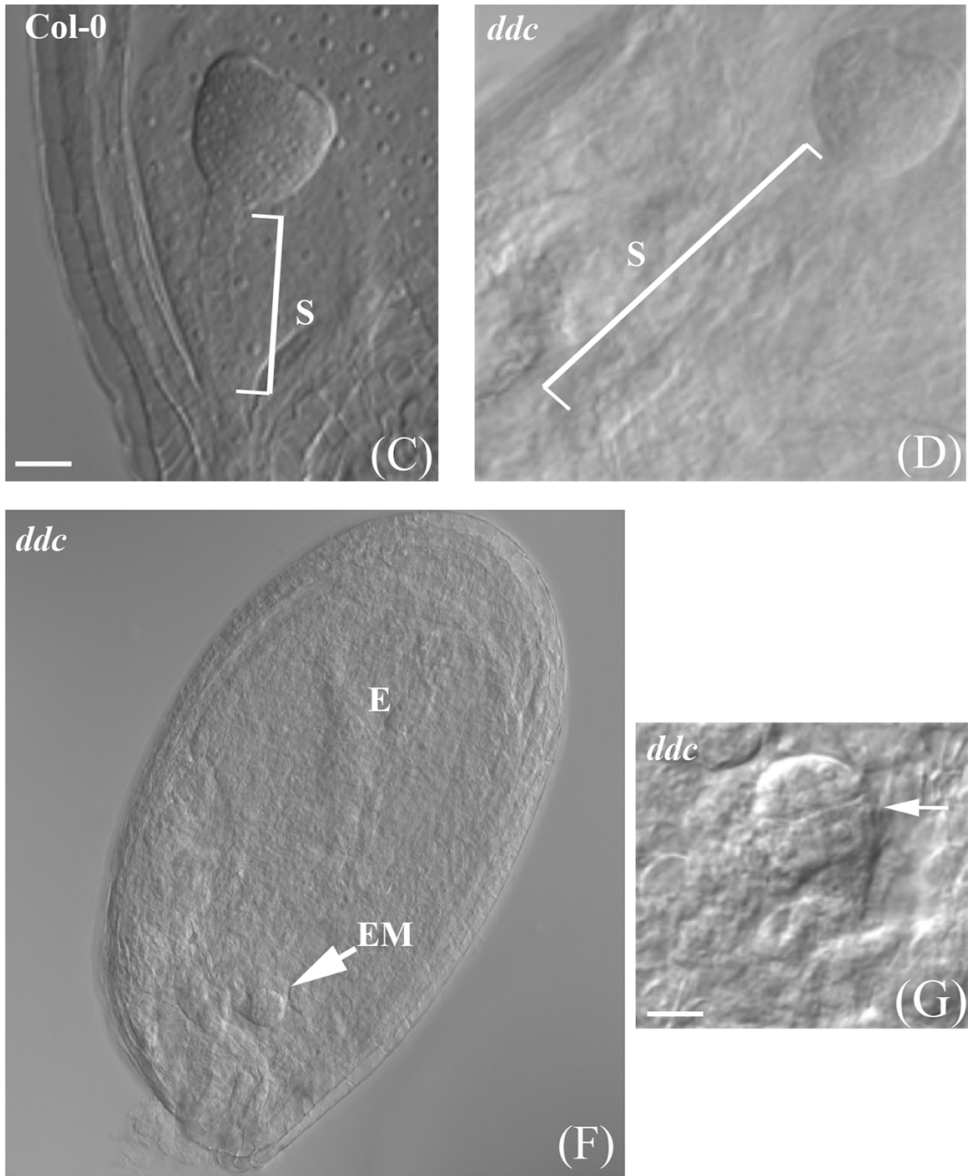

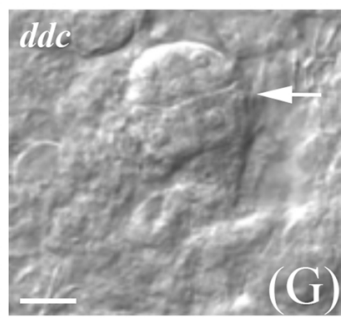

F)

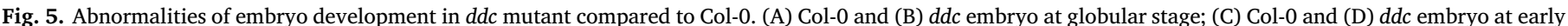

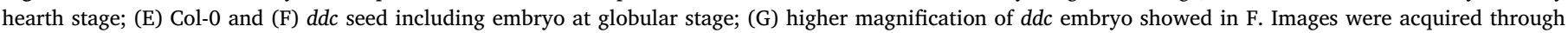

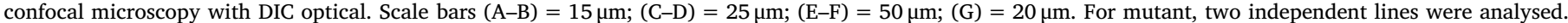
$\mathrm{EM}=$ embryo; $\mathrm{E}=$ endosperm; $\mathrm{S}=$ suspensor.
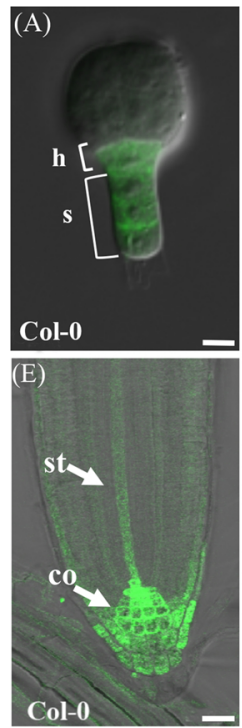
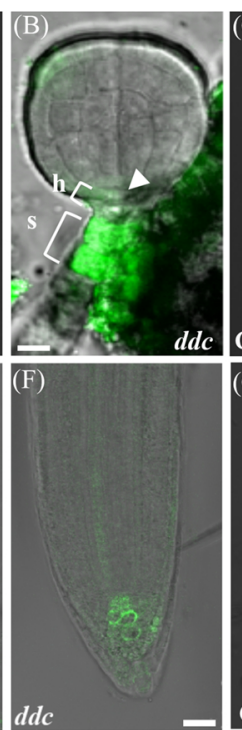
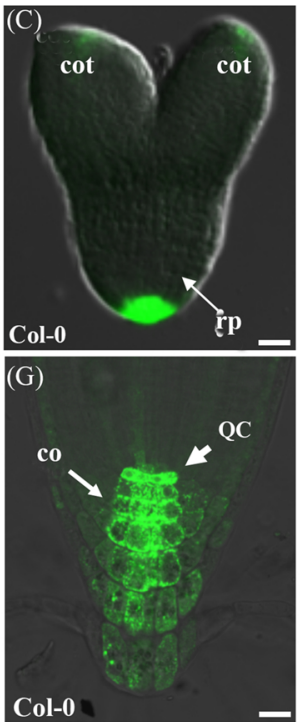
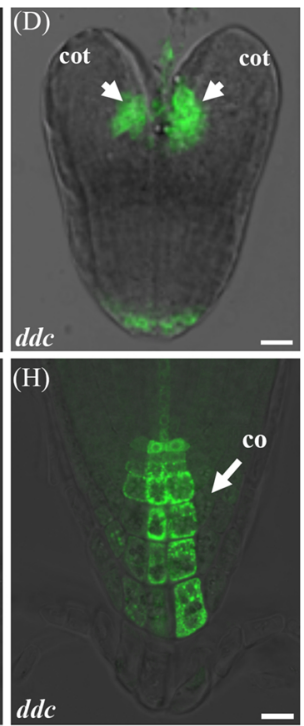
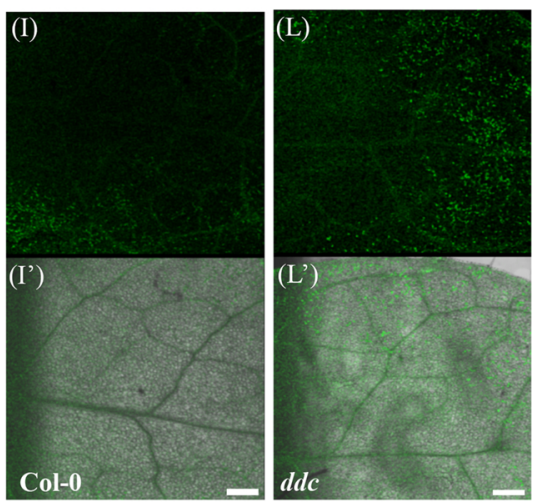

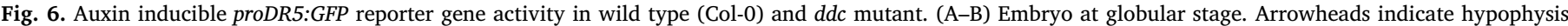

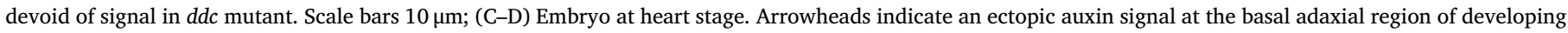

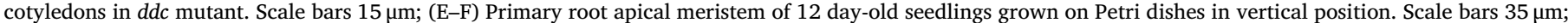

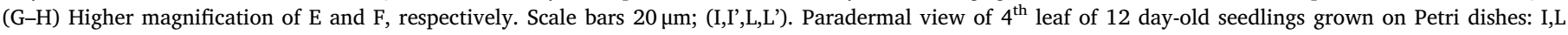

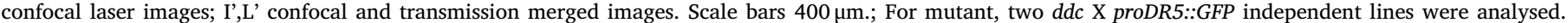
co = columella; Cot = cotyledon; $\mathrm{h}=$ Hypophysis; $\mathrm{QC}=$ quiescent centre; $\mathrm{rp}=$ root poles; $\mathrm{s}=$ suspensor; $\mathrm{st}=$ stele. 
(A)

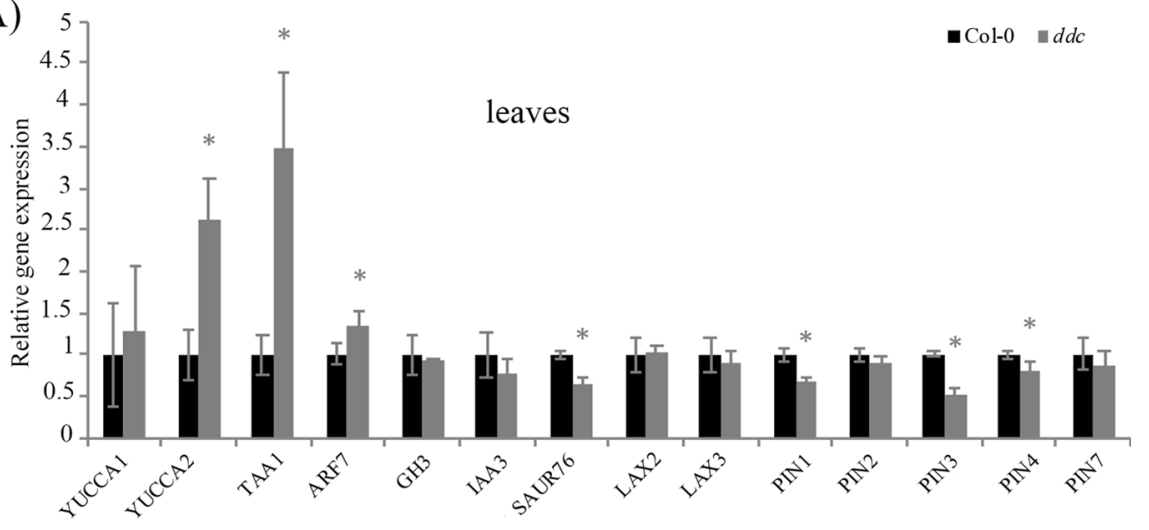

(B)

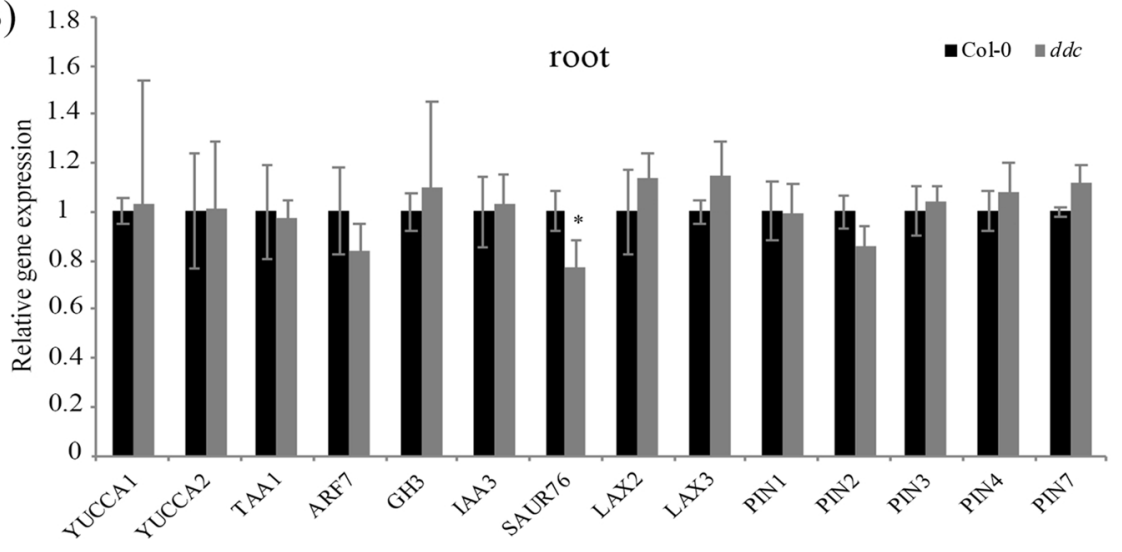

Fig. 7. Expression analysis of auxin related genes, evaluated by RT-qPCR (A) in the $3^{\text {rd }}$ and $4^{\text {th }}$ leaves and (B) in the root of 13 day-old seedlings of Col-0 and $d d c$ mutant. The RT-qPCR data were normalized using $S A N D$ and GAPDH as housekeeping genes and analyzed by qBasePLUS software. For $d d c$ mutant, two independent lines were analysed. The results represent the mean value ( \pm standard deviation) of three independent biological replicates. Asterisks indicate significant pairwise differences using Student's $t$-test ( $\mathrm{p} \leq 0.05)$. when analysing the development of aerial organs. Indeed, 21 day-old seedlings of $d d c$ mutant grown in vitro exhibited a smaller rosette area compared to Col-0 (Fig. 4A), related to a reduced area of every leaf, with the exception of leaf 8 (Fig. 4B and C). The major differences in leaf size between mutant and wild type were observed for the $3^{\text {rd }}$ and the $4^{\text {th }}$ leaf and the latter was then selected for analysing some parameters related to leaf differentiation pattern such as: epidermal pavement cell area and number, stomatal density (SD) and index (SI), xylem vein pattern (Fig. 4D-I). Morphometric measurements performed on the adaxial leaf surface showed that epidermal pavement cell area was strongly reduced in the $d d c$ mutant compared to Col-0 (Fig. 4D, Supplemental Fig. 2), while the number of cells per leaf was not significantly lower (Fig. 4E). Therefore, the smaller size of the $d d c$ leaf was only due to a reduction of cell area (Fig. 4F). In addition, the stomatal density (SD) which is a function of both the number of stomata plus the size of the epidermal pavement cells, was significantly higher in the leaf of $d d c$ mutant compared to Col-0 (Fig. 4G) and likely accounts for the quite comparable epidermis cell density in the $d d c$ mutant and Col-0 leaf (Fig. 4F, Supplemental Fig. 2). As a consequence, also the stomatal index, which normalizes for the effects of cell expansion, was higher in the $d d c$ mutant than Col-0 (Fig. $4 \mathrm{H}$ ). Concerning xylem pattern, a disconnection in some of the secondary and tertiary veins was very frequently (about $60 \pm 6 \%$ ) observed in the leaf of the $d d c$ mutant compared to the well-connected pattern observable in the wild type leaf (Fig. 4I). Finally, curled and involute leaves (i.e. curly phenotype) (Fig. 4L) were observed in adult $d d c$ plants grown in soil which globally exhibited a shorter stature than wild type plants (Supplemental Fig. 3).

Flowering time and flower morphology were not affected in the $d d c$ mutant. However, in the $d d c$ mutants, a precocious growth stop of the primary inflorescence and an overgrowth of the secondary branches, relative to the primary inflorescence was observed, clearly highlighting a reduction of apical dominance (Supplemental Fig. 3). In addition, silique length and seed production were significantly reduced with $7 \% \pm 1.5$ and $6 \% \pm 1.0$, respectively, in the mutant compared to Col-0, which correlated with the high expression of the three methyltransferase genes in flowers (Fig. 1A-C). Seed viability was tested through germination assay and in both the $d d c$ mutant and Col-0 the maximum germination percentage was achieved at the second day after sowing and was about $80 \%$ and $100 \%$, respectively. Accordingly, and more interestingly, examination of cleared seeds revealed a variety of defects in the ddc mutant during embryo development (Fig. 5). In particular, at the globular stage, $d d c$ embryo exhibited a reduced number of the suspensor's cells as compared to Col-0 (Fig. 5A and B). Later on, at early hearth stage, suspensor in $d d c$ mutant was longer and formed by a higher number of cells in $d d c$ mutant than Col-0, suggesting that in the former the arrest of cell proliferation related to the functional regression of such organ is delayed (Fig. 5C and D). Moreover, in $d d c$ mutant an asymmetric pattern of cell division was also observed in the embryo at the globular stage (Fig. 5F and G), together with an apparent disorder in endosperm histological organization as compared to Col-0 (Fig. 5E).

Globally, the growth behaviour and several defects of the $d d c \mathrm{mu}-$ tant such as the alteration in embryo development, the reduced and agravitropic root growth, the curled leaf and the altered stomatal density and vein connection, resembled phenotypes of auxin mutants [78-81], strongly supporting the hypothesis that auxin-related pathways could be altered.

\subsection{Auxin perception in the ddc mutant}

At this point, we investigated whether the pattern of auxin was altered in the $d d c$ mutant compared to Col-0 plants. To this aim, the proDR5::GFP reporter gene was introgressed in the $d d c$ mutant to visualize where auxin perception occurred during embryogenesis and in seedlings up till adult phase [82,83]. At embryo globular stage, where the auxin flow moves from suspensor upward to the embryo proper [84], fluorescent signal was correctly detected in suspensor cells and hypophysis of the wild type embryo (Fig. 6A), while in $d d c$ mutant 

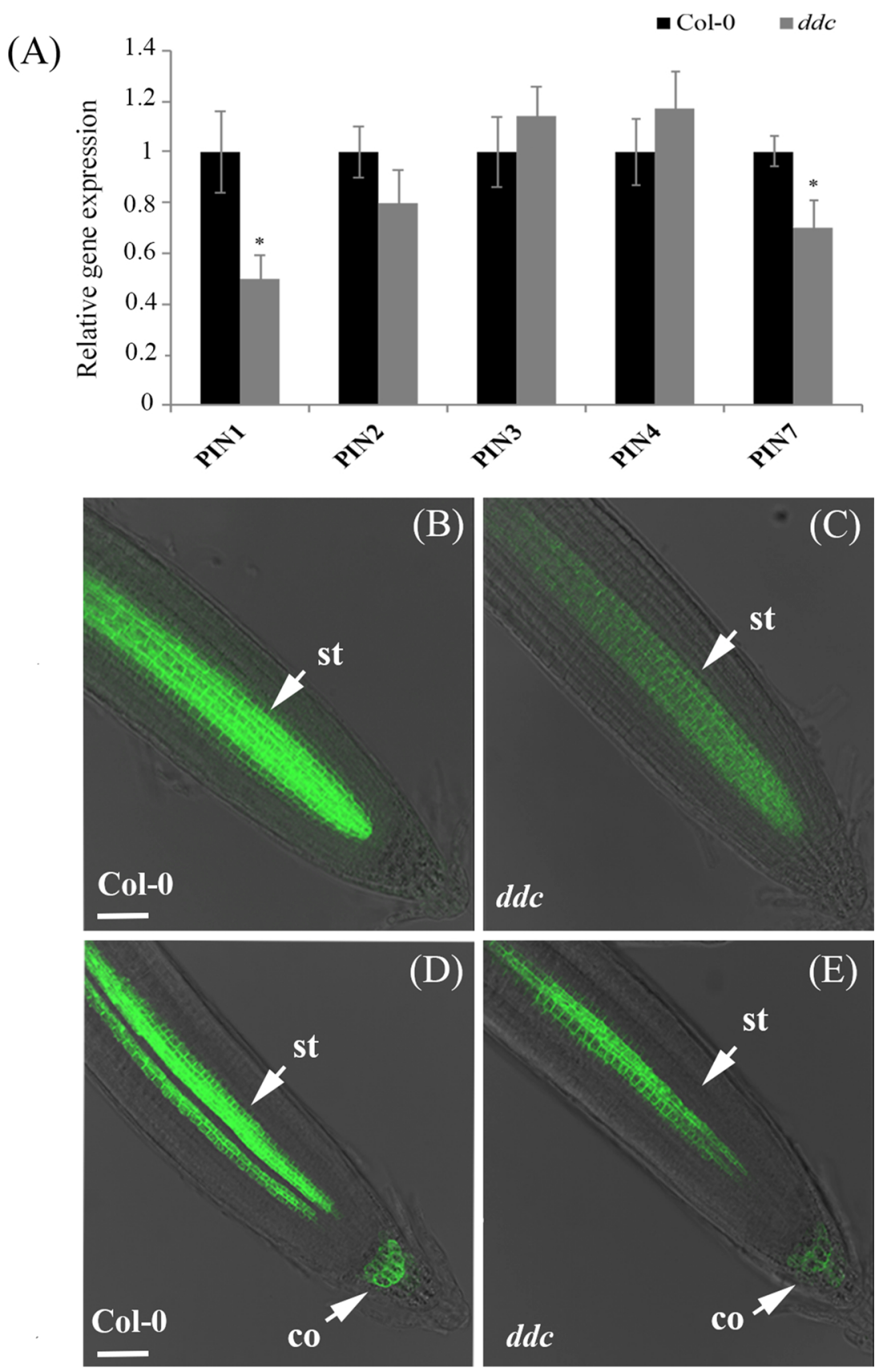

Fig. 8. (A) Expression analysis of PIN1, PIN2, PIN3, PIN4 and PIN7 genes, evaluated by RT-qPCR in the root of 6 day-old seedlings of Col-0 and $d d c$ mutant. The RT-qPCR data were normalized using $S A N D$ and $G A P D H$ as housekeeping genes and analyzed by qBasePLUS software. For $d d c$ mutant, two independent lines were analysed. The results represent the mean value ( \pm standard deviation) of three independent biological replicates. Asterisks indicate significant pairwise differences using Student's $t$-test ( $\mathrm{p} \leq 0.05)$. (B) Fluorescent signal localization of $A$. thaliana transgenic reporter line pPIN1::PIN1-GFP in wild type (Col-0) and ddc mutant. (B-C); pPIN7::PIN7-GFP in wild type (Col-0) and $d d c$ mutant (D-E), in the root of 6 day-old seedlings of Col- 0 and $d d c$ mutant. Scale bars $45 \mu \mathrm{m}$ (B-E). st = stele; co = columella. hypophysis appeared almost devoid of signal (Fig. 6B). At the heart stage, a very weak fluorescent signal was observed in the $d d c$ embryo root pole in addition to an ectopic signal at the basal adaxial region of developing cotyledons (Fig. 6D). At this stage, auxin maxima signal was mainly localised at the cotyledon's tip and flows to the radicle in Col-0 plants (Fig. 6C).

Fluorescent signal remained very weak in the $d d c$ primary root tip (Fig. 6F) compared to Col-0 (Fig. 6E) in both 6 day-old (Fig. 6E and F) and 12 day-old seedlings (data not shown), suggesting a lower auxin accumulation which is consistent with the reduced root growth in the $d d c$ mutant (Fig. 2A). In particular, a clear and visible fluorescence in the quiescent centre (Fig. 6G), along the stele (Fig. 6E) and in all the columella cells of the calyptra was observed in Col-0 roots (Fig. 6E and $\mathrm{G})$. In contrast, in the $d d c$ root an asymmetrical distribution of signal was clearly observed in the calyptra (Fig. $6 \mathrm{H}$ ), and the very weak fluorescent signal obscured a clear definition of auxin presence in the elongation zone responsible for root growth direction (Fig. 6F). Thus, we could relate the agravitropic root growth of the $d d c$ mutant to the reduced and impaired localization of auxin in the calyptra which is the gravity sensitive tissue. Strikingly, in developing leaves (i.e. $3^{\text {rd }}$ and $4^{\text {th }}$ leaf) of 12 day-old seedlings a very strong fluorescent signal was detected in the $d d c$ mutant (Fig. $6 \mathrm{~L}$ and L') compared to wild type (Fig. $6 \mathrm{I}$ and I'). The mislocalisation of the DR5 activation was observed in the $70 \%$ of the $d d c$ embryos and $80 \%$ of the analysed seedlings.

\subsection{Expression level of auxin-related genes in the ddc mutant}

In order to gain insight into the relationship between the missregulation of auxin biology and the hypomethylated status of $d d c \mathrm{mu}-$ tant, a panel of auxin-related genes was selected and their expression level was estimated by RT-qPCR (Fig. 7). The selected genes were: YUCCA1 and 2, TAA1 (TRYPTOPHAN AMINOTRANSFERASE OF ARABIDOPSIS 1) involved in auxin biosynthesis; PIN1 (PINFORMED 1) and PIN2, PIN3, PIN4, PIN7 which encode the main polar auxin efflux 

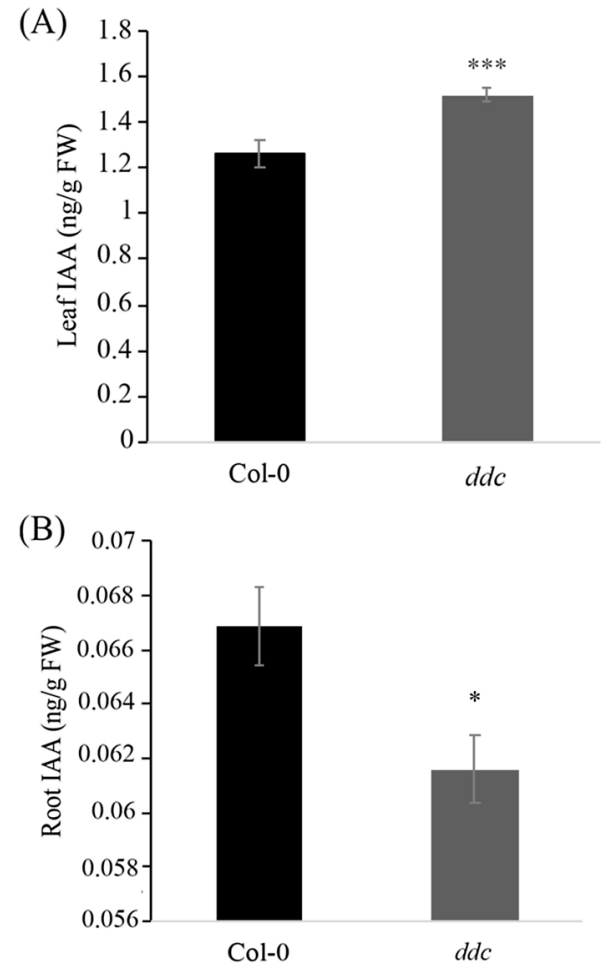

Fig. 9. GC-MSIAA relative quantification carried (A) on the $3^{\text {rd }}$ and $4^{\text {th }}$ leaves of 13 day-old seedlings of and (B) on the root of 6 old-day seedlings of Col-0 and $d d c$ mutant. For $d d c$ mutant, two independent lines were analysed. Data were analyzed through $t$-test with $\mathrm{P} \leq 0.05$ and asterisks indicate significant differences compared to the control: * $(P \leq 0.05), * *(P \leq 0.01)$, *** $(P \leq 0.001)$.

carriers; ARF7 (AUXIN RESPONSE FACTOR 7), GH3 (auxin responsive GH3 family protein), IAA3 (INDOLE-3-ACETIC ACID INDUCIBLE 3) and SAUR76 (SMALL AUXIN UP-RNA76) which work in auxin signalling.

Attention was specifically focused on the vegetative post-embryonic development and gene expression was firstly estimated in the $3^{\text {rd }}$ and $4^{\text {th }}$ leaves and in the root of 13 day-old seedling (Fig. 7). Significant differences in the expression level of the selected genes were observed specifically in the leaves. Indeed, auxin biosynthesis-related genes such as YUCCA2 and TAA1 were up-regulated more than two-fold in the leaves of the $d d c$ mutant $v s$ Col-0, together with $A R F 7$, encoding an auxin response factor, which also showed a significantly higher level of transcripts compared to wild type (Fig. 7A). Concomitantly, a significant down-regulation of the expression of SAUR76 and, more interestingly, of PIN1, PIN3 and PIN4 which encode auxin carriers, was also detected in the leaves of $d d c$ mutant (Fig. 7A). In addition, the level of IAA, estimated in the 3rd and $4^{\text {th }}$ leaves through a GC-MS approach, was found to be $20 \%$ higher in the $d d c$ mutant than in Col-0 (Fig. 9A).

No differences were instead observed in the roots of 13 day-old seedlings for all the analysed genes, with the exception of SAUR76 which resulted down-regulated (Fig. 7B). Therefore, we planned to extend the analysis of PIN gene expression to the root of 6 day-old seedlings, where agravitropic behaviour (Fig. 3A,B) and altered auxin distribution (Fig. 6E-H) were uncovered. In this case, a clear downregulation of PIN1 and PIN7 genes was observed (Fig. 8A).

\subsection{PIN distribution in the ddc primary root}

In order to verify whether the reduced expression of PIN1 and PIN7 genes was accompanied by a reduced presence of these rate-limiting auxin carriers, we investigated on the distribution of PIN1 and PIN7 proteins in the same-aged roots, by using $A$. thaliana transgenic reporter lines: pPIN1::PIN1-GFP, and pPIN7::PIN7. In line with gene expression data, a weaker fluorescent signal of pPIN1::PIN1-GFP as well as of
pPIN7::PIN7-GFP was observed both in the stele and in columella cells of $d d c$ roots compared to Col-0 (Fig. 8B-E), clearly supporting an impairment of auxin transport in the root of 6 day-old $d d c$ seedlings. In agreement with this hypothesis, the IAA level in the root of the $d d c$ mutant was $8 \%$ lower as compared to the one in Col-0 (Fig. 9B).

\subsection{Cytosine methylation at auxin-related genes in the ddc mutant}

DNA methylation at and near gene promoters plays a role in mediating gene expression. Thus, we next verified whether the overexpression of auxin-related genes in the leaves of the $d d c$ mutant was associated with reduced methylation levels within their promoters and/ or coding regions. To this aim, Methylated DNA Immunoprecipitation followed by qPCR (MeDIP-qPCR) analysis of genomic DNA fragments was performed on the $3^{\text {rd }}$ and $4^{\text {th }}$ leaves of 13 day-old seedlings. The MeDIP approach was then extended to auxin-related genes, by using HEIIO [85] as the control sample (see materials and methods) and all the samples were normalized to ACTIN7 gene and $v$ s input sample. The DNA fragments obtained after MeDIP, were quantified by qPCR analysis using 3 or 4 pairs of primers designed to amplify about $150 \mathrm{bp}$ long regions within 1000-1500 bp upstream or immediately downstream the ATG codons of each gene (Fig. 10B-D). The primers were placed in the region that we considered as methylation "hot spot". The results showed a statistically significant decrease of DNA methylation around $1.2 \mathrm{~kb}$ upstream of the ATG site of YUCCA2 in the $d d c$ mutant compared to Col-0 (Fig. 10B'). In contrast, methylation levels of different regions in the TAA1 and ARF7 genes did not significantly differ between the $d d c$ mutant and Col-0 (Fig. 10C' and D').

\section{Discussion}

In the present work we used the $d d c$ triple mutant, defective in both maintenance and de novo DNA methylation to identify developmental pathways under the regulation of DNA methyl transferases.

Previously, several abnormalities such as a reduced vegetative growth and impaired female and male gametogenesis, embryogenesis and seed viability were detected in met 1 single mutant of $A$. thaliana, together with an indirect interaction with auxin pathway $[11,54,57]$. By contrast, mutations in either DRMs or CMT3 did not result into visible phenotypes suggesting that the two gene classes act in a partially redundant manner $[15,17]$. In the Landsberg erecta (Ler) ecotype, also the drm1 drm2 double mutant did not show morphological differences from the wild type. Whereas the triple $d d c$ mutant exhibited pleiotropic phenotypic abnormalities such as a reduced plant size, twisted leaf shape and reduced seed production, likely due to the knocking out of the functional redundancy of DRMs and CMT3 $[55,56]$.

In our study, novel phenotypic abnormalities were identified in the Arabidopsis thaliana ddc mutant in the Columbia background, such as defects during embryo development, reduced and agravitropic primary root growth, reduced leaf growth and differentiation consisting of reduced cell size, an increased stomatal density and index and an altered leaf vein pattern.

Preliminary evaluation of the DRM1, DRM2 and CMT3 expression in the different organs of $A$. thaliana wild type plants allowed us to verify that all the genes were expressed in the various organs although in some of them at largely different levels. In particular, DRM1 and CMT3 genes exhibited the highest expression in the flower. Such pattern indicated that they have a major function in reproductive tissue, as evidenced by reduced seed density observed in $d d c$ mutant, as well as in young developing organs rather than in adult ones characterised by fully differentiated tissues.

In line with this assumption, phenotypic alterations in the $d d c$ mutant were observed both in the embryo and in developing organs of adult plant in association with defective auxin distribution and/or level as verified through the proDR5::GFP marker gene and IAA quantification, respectively. Namely, in $d d c$ embryo an ectopic signal of auxin 


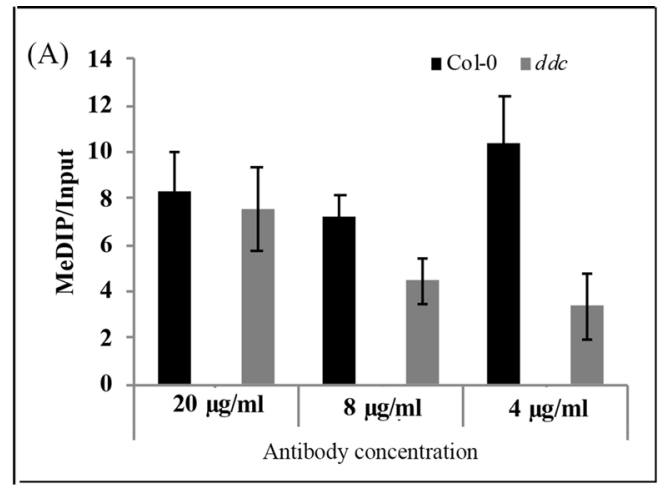

(B)
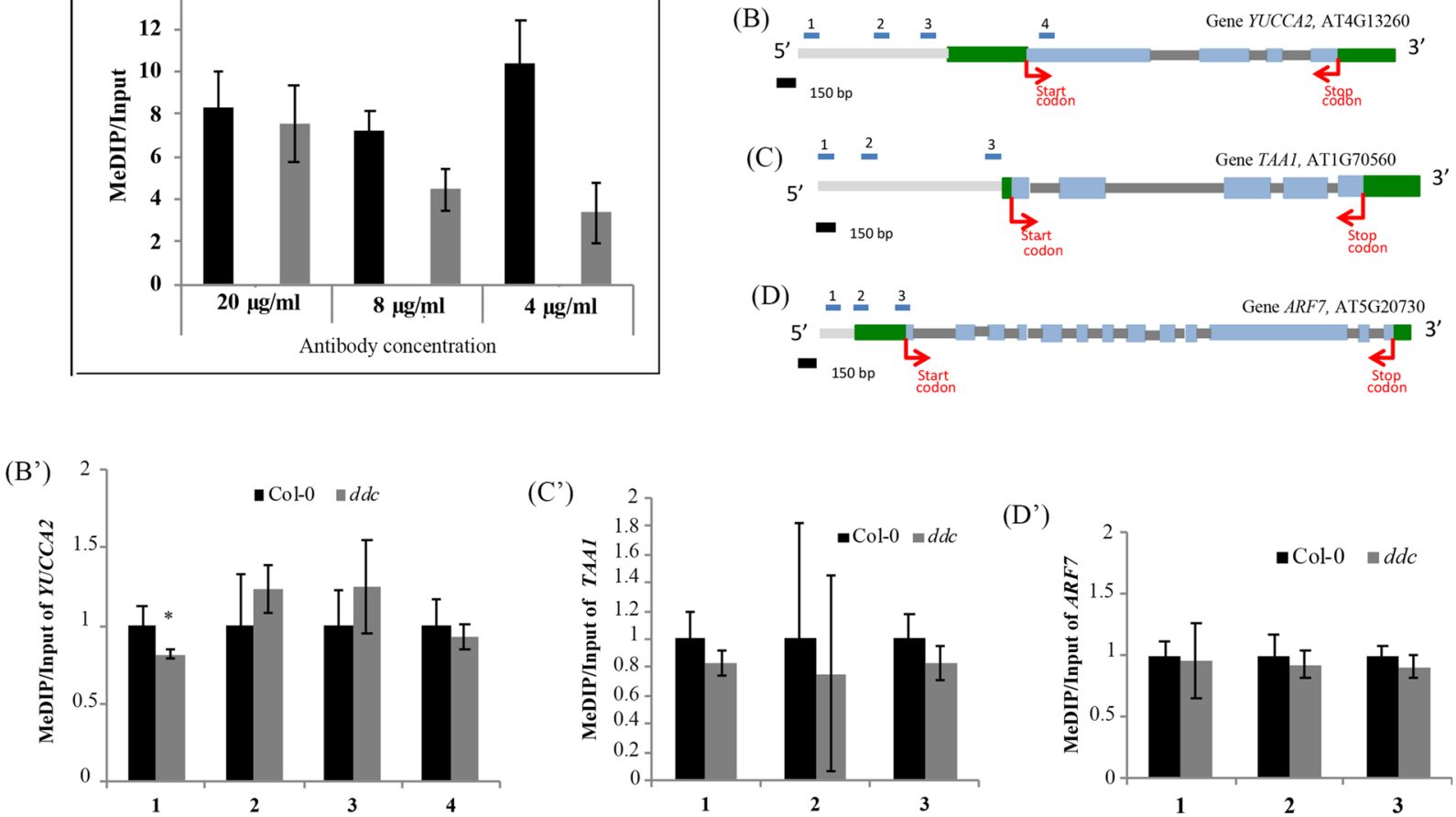

Fig. 10. Analysis of gene-specific methylation level, through MeDIP-qPCR, performed on $3^{\text {rd }}$ and $4^{\text {th }}$ leaves of 13 day-old seedlings grown on soil. In the box (A) methylation level of HEI1O gene, estimated by using different concentration of antibody anti 5-methylcytosine to optimize the protocol and select the antibody concentration to be used. (B-D) Structure of analysed genes: the numbers 1-4 indicate the position of primers. Green and blue boxes represent untranslated region and exons, respectively; start and the stop codons are indicated with red. (B', C', D') Relative amount of immunoprecipitation DNA fragments determined by RT-qPCR analysis of (A') YUCCA2 (B') TAA1 and (C') ARF7 genes. The immunoprecipitated fractions were normalized versus both input and the ACTIN7 gene. For ddc mutant, two independent lines were analysed. The results represent the mean value ( \pm standard deviation) of three independent biological replicates. Asterisks indicate significant pairwise differences using Student's t-test $(\mathrm{p} \leq 0.05)$ (For interpretation of the references to colour in this figure legend, the reader is referred to the web version of this article).

perception was detected suggesting an alteration in the establishment of auxin gradients required for a correct embryo development $[82,83]$. An alteration of auxin distribution and level was also uncovered in leaf and root during post-embryonic development. Indeed, these results strongly suggested that auxin biosynthesis could be enhanced in the leaves of $d d c$ mutant. In particular a lower presence of this hormone was detected in the primary root of the $d d c$ triple mutant compared to that of wild-type and mainly in the calyptra which represents the gravity sensing tissue. Additionally, the reduced presence of the PIN1 and PIN7 proteins in $d d c$ roots containing pPIN1::PIN1-GFP and pPIN7::PIN7-GFP reporters demonstrated that the above pattern was related to a reduced auxin flow. Notably, the root of the $d d c$ mutant exhibited a reduced length and a stronger bending of the primary root compared to the wild type plants, which are also reported in auxinrelated mutants such as aux1-7 [79], pin2 eir1-1 [78]. Therefore, in the $d d c$ root, a clear correlation was observed between the alteration in the level and distribution of auxin and its crucial role for proper root development and correct gravity response, acting as central mediator of gravitropic stimulus [86].

In the leaves of the $d d c$ mutant, a higher accumulation of auxin was detected that was associated with the overexpression of genes involved in auxin pathway, such as TAA1 and ARF7 YUCCA2. However, the increased expression levels of TAA1 and ARF7 genes in the leaf of $d d c$ mutant could be related only to an indirect effect of altered DNA methylation status in other genome regions since these genes were not differentially methylated. On the contrary, the reduced DNA methylation levels detected upstream the 5 '-end of YUCCA2 associated to its upregulation identified this gene as a direct target of the methylationrelated epigenetic mechanism. These results are fully consistent with the curly leaf phenotype and altered leaf differentiation of the $d d c$ triple mutant, which are tightly controlled by auxin level [83]. In addition, and very interestingly, a downregulation of several members of the PIN gene family, which encode auxin-efflux carriers was also observed in the leaf of the $d d c$ mutant. A shift in the polarization of the membranelocalized PIN proteins, from a localization leading to auxin maximum towards incipient primordium to a basal localization towards the developing leaf, is quite essential for the growth and differentiation of leaf [87]. Accordingly, mutations in members of auxin transporters are associated with spatially disorganized initiation of leaf primordia as well as with narrow and downwardly rolled rosette leaves [88]. Thus, based on the obtained results, we propose that the affected leaf phenotype of the $d d c$ mutant is related to an overproduction of auxin, coupled to an impaired translocation through the PIN proteins, that directly influence the amount and direction of auxin flow during leaf development. The presence of disconnections in the $d d c$ leaf vasculature strengthened the assumption of an altered auxin distribution [81].

Notably, in the $d d c$ mutant the secondary inflorescence was found to slightly exceed the primary inflorescence which stops its growth, highlighting a reduced apical dominance. Therefore, based on all these results a general impairment of auxin distribution likely occurs in the $d d c$ mutant. Finally, these results provide further evidences on how auxin transport regulates bud outgrowth [89].

Interestingly, our results also showed that the YUCCA2 gene was a direct target for methylation by the combined action of DRMs and/or CMT3 methyltransferases. Namely, after optimization of the experimental set-up of the MeDIP assay which allowed to identify genomic differences in DNA methylation, we demonstrated that the promoter region of the YUCCA2 gene was hypomethylated in the leaf of the $d d c$ mutant. It is known that the methylation at the gene promoter region prevents the binding of transcription factors to their target sequences 
and, as a consequence, a reduced methylation at promoters can result in gene activation [35-40]. For example, promoter hyper- and hypomethylation, specifically dependent on MET1 and DRM2 methyltransferases, and gene transcriptional regulation has been demonstrated in Arabidopsis cell suspensions in relation to cell dedifferentiation $[58,60]$. Therefore, hypomethylation in the promoter region of the YUCCA2 gene coupled to its overexpression, specifically in the genome of the $3^{\text {rd }}$ and $4^{\text {th }}$ developing leaf, highlighted a direct organ-specific modulation of this gene by a methylation-related mechanism.

In this context, an interesting aspect that need to be mentioned is that the relationship between auxin biology and DNA methylation can be yet more complex. Namely, in Arabidopsis cell suspensions the depletion of the 1-Naphthaleneacetic acid (NAA) auxin in the medium was found to induce a loss of methylation in the promoters of specific genes $[58,60]$. Thus, a feedback loop mechanism could play a role in modulating such interaction.

Finally, among auxin-related genes differentially expressed in the $d d c$ mutant, the auxin signalling related SAUR76 gene was downregulated in both leaf and root, despite in $d d c$ leaves auxin amount was higher than in Col-0. Taking into account the complexity of the methylation defective background of the $d d c$ mutant, a more intricate and organ-specific regulatory network can be hypothesized which needs to be further investigated.

In conclusion, through the functional analysis of the $d d c$ triple mutant of Arabidopsis thaliana, we demonstrated that both maintenance and de novo methylation play a key role in the transcriptional control of genes related to auxin pathways, from biosynthesis to transport and signalling, which are relevant in the regulation of plant development. For some of these genes, an organ-specific modulation has been demonstrated showing that, in the interweaved landscape of different transcriptional networks, the pattern of DNA methylation is dynamic and correlated with organ-specific growth.

\section{Conflict of interest}

The authors declare that they have no conflicts of interest with the contents of this article.

\section{Author contributions}

MBB, LB, AC, MG, MVL designed research; FA, LB, IF, MG, MW, MP, performed research; MRA, MBB, LB, AC, IF, MP, MVL, MW analysed data and discussed results; MBB, LB, IF, wrote the paper. All authors contributed to improve the paper and approved the final manuscript.

\section{Acknowledgements}

This work was founded by grants from University of Calabria (MIUR - ex 60\%). IF is indebted to PhD from the Italian Ministry for research and Technology (MIUR). We are indebted to Robert L. Fisher for generously making available Arabidopsis pro:DR5::GFP reporter lines. The confocal scanning laser microscope for this research were supplied by PON Ricerca e Competitività 2007-2013, Sistema Integrato di Laboratori per L'Ambiente - (SILA) PONa3_00341, CM2-Centro di

Microscopia e Microanalisi.

\section{Appendix A. Supplementary data}

Supplementary material related to this article can be found, in the online version, at doi:10.1016/j.plantsci.2018.12.029.

\section{References}

[1] R. Bonasio, S. Tu, D. Reinberg, Molecular signals of epigenetic states, Science 330 (2010) 612-616, https://doi.org/10.1126/science.1191078.

[2] C. Becker, J. Hagmann, J. Müller, D. Koenig, O. Stegle, K. Borgwardt, D. Weigel,
Spontaneous epigenetic variation in the Arabidopsis thaliana methylome, Nature 480 (2011) 245-249.

[3] M. Lauria, V. Rossi, Epigenetic control of gene regulation in plants, Biochim. Biophys. Acta 1809 (2011) 369-378, https://doi.org/10.1016/j.bbagrm.2011.03. 002 .

[4] C.S. Pikaard, O. Mittelsten Scheid, Epigenetic regulation in plants, Cold Spring Harb. Perspect. Biol. 6 (2014) 019315, , https://doi.org/10.1101/cshperspect. a019315.

[5] R.J. Schmitz, M.D. Schultz, M.G. Lewsey, R.C. O'Malley, M.A. Urich, O. Libiger, N.J. Schork, J.R. Ecker, Transgenerational epigenetic instability is a source of novel methylation variants, Science 334 (2011) 369-373, https://doi.org/10.1126/ science. 1212959.

[6] X. Wang, D. Moazed, DNA sequence-dependent epigenetic inheritance of gene silencing and histone H3K9 methylation, Science 356 (2017) 88-91, https://doi.org/ $10.1126 /$ science.aaj2114.

[7] S.J. Cokus, S. Feng, X. Zhang, Z. Chen, B. Merriman, C.D. Haudenschild, S. Pradhan, S.F. Nelson, M. Pellegrini, S.E. Jacobsen, Shotgun bisulphite sequencing of the Arabidopsis genome reveals DNA methylation patterning, Nature 452 (2008) 215-219, https://doi.org/10.1038/nature06745.

[8] D. Fujimoto, P.R. Srinivasan, E. Borek, On the nature of the deoxyribonucleic acid methylases. Biological evidence for the multiple nature of the enzymes, Biochemistry 4 (1965) 2849-2855.

[9] H. Saze, K. Tsugane, T. Kanno, T. Nishimura, DNA methylation in plants: relationship to small RNAs and histone modifications, and functions in transposon inactivation, Plant Cell Physiol. 53 (2012) 766-784, https://doi.org/10.1093/pcp/ pcs008.

[10] P. Cubas, C. Vincent, E. Coen, An epigenetic mutation responsible for natural variation in floral symmetry, Nature 401 (1999) 157-161.

[11] E.J. Finnegan, W.J. Peacock, E.S. Dennis, Reduced DNA methylation in Arabidopsis thaliana results in abnormal plant development, Proc. Natl. Acad. Sci. U. S. A. 93 (1996) 8449-8454.

[12] T.H. Bestor, Activation of mammalian DNA methyltransferase by cleavage of a $\mathrm{Zn}$ binding regulatory domain, EMBO J. 11 (1992) 2611-2617.

[13] X. Cao, N.M. Springer, M.G. Muszynski, R.L. Phillips, S. Kaeppler, S.E. Jacobsen, Conserved plant genes with similarity to mammalian de novo DNA methyltransferases, Proc. Natl. Acad. Sci. U. S. A. 97 (2000) 4979-4984.

[14] N. Kishimoto, H. Sakai, J. Jackson, S.E. Jacobsen, E.M. Meyerowitz, E.S. Dennis, E.J. Finnegan, Site specificity of the Arabidopsis METI DNA methyltransferase demonstrated through hypermethylation of the superman locus, Plant Mol. Biol. 46 (2001) 171-183.

[15] A.M. Lindroth, X. Cao, J.P. Jackson, D. Zilberman, C.M. McCallum, S. Henikoff, S.E. Jacobsen, Requirement of CHROMOMETHYLASE3 for maintenance of CpXpG methylation, Science 292 (2001) 2077-2080.

[16] C.M. Papa, N.M. Springer, M.G. Muszynski, R. Meeley, S.M. Kaeppler, Maize chromomethylase Zea methyltransferase 2 is required for $\mathrm{CpNpG}$ methylation, Plant Cell 13 (2001) 1919-1928.

[17] X. Cao, S.E. Jacobsen, Role of the Arabidopsis DRM methyltransferases in de novo DNA methylation and gene silencing, Curr. Biol. 12 (2002) 1138-1144, https://doi. org/10.1016/S0960-9822(02)00925-9.

[18] M.A. Matzke, T. Kanno, A.J. Matzke, RNA-directed DNA methylation: the evolution of a complex epigenetic pathway in flowering plants, Annu. Rev. Plant Biol. 66 (2015) 243-267, https://doi.org/10.1146/annurev-arplant-043014-114633.

[19] X. Cao, W. Aufsatz, D. Zilberman, M.F. Mette, M.S. Huang, M. Matzke, S.E. Jacobsen, Role of the DRM and CMT3 methyltransferases in RNA-directed DNA methylation, Curr. Biol. 13 (2003) 2212-2217.

[20] S.W. Chan, I.R. Henderson, S.E. Jacobsen, Gardening the genome: DNA methylation in Arabidopsis thaliana, Nat. Rev. Genet. 6 (2005) 351-360, https://doi.org/10. 1038/nrg1601.

[21] A. Zemach, I.E. McDaniel, P. Silva, D. Zilberman, Genome-wide evolutionary analysis of eukaryotic DNA methylation, Science 328 (2010) 916-919, https://doi.org/ 10.1126 /science.1186366.

[22] R. Liu, A. How-Kit, L. Stammitti, E. Teyssier, D. Rolin, A. Mortain-Bertrand, S. Halle, M. Liu, J. Kong, C. Wu, C. Degraeve-Guibault, N.H. Chapman, M. Maucourt, T.C. Hodgman, J. Tost, M. Bouzayen, Y. Hong, G.B. Seymour, J.J. Giovannoni, P. Gallusci, A DEMETER-like DNA demethylase governs tomato fruit ripening, Proc. Natl. Acad. Sci. U. S. A. 112 (2015) 10804-10809.

[23] X. Zhang, J. Yazaki, A. Sundaresan, S. Cokus, S.W. Chan, H. Chen, I.R. Henderson, P. Shinn, M. Pellegrini, S.E. Jacobsen, J.R. Ecker, Genome-wide high-resolution mapping and functional analysis of DNA methylation in Arabidopsis, Cell. 126 (2006) 1189-1201, https://doi.org/10.1016/j.cell.2006.08.003.

[24] S.R. Eichten, R. Briskine, J. Song, Q. Li, R. Swanson-Wagner, P.J. Hermanson, A.J. Waters, E. Starr, P.T. West, P. Tiffin, C.L. Myers, M.W. Vaughn, N.M. Springer, Epigenetic and genetic influences on DNA methylation variation in maize populations, Plant Cell 25 (2013) 2783-2797, https://doi.org/10.1105/tpc.113.114793.

[25] R.J. Schmitz, M.D. Schultz, M.A. Urich, J.R. Nery, M. Pelizzola, O. Libiger, A. Alix, R.B. McCosh, H. Chen, N.J. Schork, J.R. Ecker, Patterns of population epigenomic diversity, Nature 495 (2013) 193-198.

[26] X. Zhong, J. Du, C.J. Hale, J. Gallego-Bartolome, S. Feng, J. Chory, J.A. Wohlschlegel, D.J. Patel, S.E. Jacobsen, Molecular mechanism of action of plant DRM de novo DNA methyltransferases, Cell 157 (2014) 1050-1060.

[27] M.Y. Kim, D. Zilberman, DNA methylation as a system of plant genomic immunity, Trends Plant Sci. 19 (2014) 320-326, https://doi.org/10.1016/j.tplants.2014.01. 014.

[28] J.A. Rodrigues, D. Zilberman, Evolution and function of genomic imprinting in plants, Genes Dev. 29 (2015) 2517-2531, https://doi.org/10.1101/gad.269902. 115. 
[29] D. Zilberman, M. Gehring, R.K. Tran, T. Ballinger, S. Henikoff, Genome-wide analysis of Arabidopsis thaliana DNA methylation uncovers an interdependence between methylation and transcription, Nat. Genet. 39 (2007) 61-99, https://doi.org/10. 1038/ng1929.

[30] M. Chen, S. Lv, Y. Meng, Epigenetic performers in plants, Dev. Growth Differ 52 (2010) 555-566.

[31] A.J. Bewick, C.E. Niederhuth, L. Ji, N.A. Rohr, P.T. Griffin, J. Leebens-Mack, R.J. Schmitz, The evolution of CHROMOMETHYLASES and gene body DNA methylation in plants, Genome Biol. 18 (2017) 65 doi: 0.1186/s13059-017-1195-1.

[32] S. Takuno, B.S. Gaut, Gene body methylation is conserved between plant orthologs and is of evolutionary consequence, Proc. Natl. Acad. Sci. U. S. A. 110 (2013) 1797-1802, https://doi.org/10.1073/pnas.1215380110.

[33] A.J. Bewick, R.J. Schmitz, Gene body DNA methylation in plants, Curr. Opin. Plant Biol. 36 (2017) 103-110, https://doi.org/10.1016/j.pbi.2016.12.007.

[34] D. Zilberman, An evolutionary case for functional gene body methylation in plants and animals, Genome Biol. 18 (2017) 87, https://doi.org/10.1186/s13059-0171230-2.

[35] S.M. Iguchi-Ariga, W. Schaffner, CpG methylation of the cAMP-responsive enhancer/promoter sequence TGACGTCA abolishes specific factor binding as well as transcriptional activation, Genes Dev. 3 (1989) 612-619.

[36] N.M. Inamdar, K.C. Ehrlich, M. Ehrlich, CpG methylation inhibits binding of several sequence-specific DNA-binding proteins from pea, wheat, soybean and cauliflower, Plant Mol. Biol. 17 (1991) 111-123.

[37] A.C. Bell, G. Felsenfeld, Methylation of a CTCF-dependent boundary controls imprinted expression of the Igf2 gene, Nature 405 (2000) 482-485, https://doi.org/ $10.1038 / 35013100$.

[38] M.R. Campanero, M.I. Armstrong, E.K. Flemington, CpG methylation as a mechanism for the regulation of E2F activity, Proc. Natl. Acad. Sci. U. S. A. 97 (2000) 6481-6486, https://doi.org/10.1073/pnas.100340697.

[39] A.T. Hark, C.J. Schoenherr, D.J. Katz, R.S. Ingram, J.M. Levorse, S.M. Tilghman, CTCF mediates methylation-sensitive enhancer-blocking activity at the H19/Igf2 locus, Nature 405 (2000) 486-489, https://doi.org/10.1038/35013106.

[40] F. Scebba, G. Bernacchia, M. De Bastiani, M. Evangelista, R.M. Cantoni, R. Cella, M.T. Locci, L. Pitto, Arabidopsis MBD proteins show different binding specificities and nuclear localization, Plant Mol. Biol. 53 (2003) 715-731.

[41] R.H. Dowen, M. Pelizzola, R.J. Schmitz, R. Lister, J.M. Dowen, J.R. Nery, J.E. Dixon, J.R. Ecker, Widespread dynamic DNA methylation in response to biotic stress, Proc. Natl. Acad. Sci. U. S. A. 109 (2012) 2183-2191, https://doi.org/10. 1073/pnas.1209329109.

[42] M. Greco, A. Chiappetta, L. Bruno, M.B. Bitonti, In Posidonia oceanica cadmium induces changes in DNA methylation and chromatin patterning, J. Exp. Bot. 63 (2012) 695-709, https://doi.org/10.1093/jxb/err313.

[43] M. Greco, A. Chiappetta, L. Bruno, M.B. Bitonti, Effects of light deficiency on genome methylation in Posidonia oceanica, Mar. Ecol. Prog. Ser. 473 (2013) 103-114, https://doi.org/10.3354/meps09955.

[44] P.P. Sahu, G. Pandey, N. Sharma, S. Puranik, M. Muthamilarasan, M. Prasad, Epigenetic mechanisms of plant stress responses and adaptation, Plant Cell Rep. 32 (2013) 1151-1159, https://doi.org/10.1007/s00299-013-1462-x.

[45] S. Zhong, Z. Fei, Y. Chen, Y. Zheng, M. Huang, J. Vrebalov, R. McQuinn, N. Gapper, B. Liu, J. Xiang, Y. Shao, J.J. Giovannoni, Single-base resolution methylomes of tomato fruit development reveal epigenome modifications associated with ripening, Nat. Biotech. 31 (2013) 154-161, https://doi.org/10.1038/nbt.2462.

[46] D.C. Baulcombe, C. Dean, Epigenetic regulation in plant responses to the environment, Cold Spring Harb. Perspect. Biol. 6 (2014) a019471, , https://doi.org/10. 1101/cshperspect.a019471.

[47] J. Candaele, K. Demuynck, D. Mosoti, G.T. Beemster, D. Inzé, H. Nelissen, Differential methylation during maize leaf growth targets developmentally regulated genes, Plant Physiol. 164 (2014) 1350-1364, https://doi.org/10.1104/pp. 113.233312.

[48] M. García-Aguilar, C.S. Gillmor, Zygotic genome activation and imprinting: parentof-origin gene regulation in plant embryogenesis, Curr. Opin. Plant Biol. 27 (2015) 29-35, https://doi.org/10.1016/j.pbi.2015.05.020.

[49] P. Gallusci, C. Hodgman, E. Teyssier, G.B. Seymour, DNA methylation and chromatin regulation during fleshy fruit development and ripening, Front. Plant Sci. 7 (2016) 807, https://doi.org/10.3389/fpls.2016.00807.

[50] S. Farinati, A. Rasori, S. Varotto, C. Bonghi, Rosaceae Fruit Development, Ripening and Post-harvest: An Epigenetic Perspective, Front. Plant Sci. 8 (2017) 1247, https://doi.org/10.3389/fpls.2017.01247.

[51] J. Giovannoni, C. Nguyen, B. Ampofo, S. Zhong, Z. Fei, The Epigenome and Transcriptional Dynamics of Fruit Ripening, Annu. Rev. Plant Biol. 68 (2017) 61-84, https://doi.org/10.1146/annurev-arplant-042916-040906.

[52] G. Wang, C. Köhler, Epigenetic processes in flowering plant reproduction, J. Exp. Bot. 68 (2017) 797-807, https://doi.org/10.1093/jxb/erw486.

[53] M.J. Ronemus, M. Galbiati, C. Ticknor, J. Chen, S.L. Dellaporta, Demethylationinduced developmental pleiotropy in Arabidopsis, Science. 273 (1996) 654-657, https://doi.org/10.1126/science.273.5275.654.

[54] X. Cao, S.E. Jacobsen, Locus-specific control of asymmetric and CpNpG methylation by the DRM and CMT3 methyltransferase genes, Proc. Natl. Acad. Sci. U. S. A. 99 (2002) 16491-16498.

[55] S.W. Chan, I.R. Henderson, X. Zhang, G. Shah, J.S. Chien, S.E. Jacobsen, RNAi, DRD1, and histone methylation actively target developmentally important non-CG DNA methylation in Arabidopsis, PLoS Genet. 2 (2006) e83.

[56] W. Xiao, K.D. Custard, R.C. Brown, B.E. Lemmon, J.J. Harada, R.B. Goldberg, R.L. Fischer, DNA methylation is critical for Arabidopsis embryogenesis and seed viability, Plant Cell 18 (2006) 805-814, https://doi.org/10.1105/tpc.105.038836.

[57] M. Berdasco, R. Alcázar, M.V. García-Ortiz, E. Ballestar, A.F. Fernández, T. Roldán-
Arjona, A.F. Tiburcio, T. Altabella, N. Buisine, H. Quesneville, A. Baudry, L. Lepiniec, M. Alaminos, R. Rodríguez, A. Lloyd, V. Colot, J. Bender, M.J. Canal, M. Esteller, M. Fraga, Promoter DNA hypermethylation and gene repression in undifferentiated Arabidopsis cells, PLoS One 3 (10) (2008) e3306, , https://doi.org/ 10.1371/journal.pone.0003306 1.

[58] H. Nelissen, S. De Groeve, D. Fleury, P. Neyt, L. Bruno, M.B. Bitonti, F. Vandenbussche, D. Van der Straeten, T. Yamaguchi, H. Tsukaya, E. Witters, G. De Jaeger, A. Houben, M. Van Lijsebettens, Plant Elongator regulates auxin-related genes during RNA polymerase II transcription elongation, Proc. Natl. Acad. Sci. U. S. A. 107 (2010) 1678-1683, https://doi.org/10.1073/pnas.0913559107.

[59] F. Jiang, Z. Feng, H. Liu, J. Zhu, Involvement of plant stem cells or stem cell-like cells in Dedifferentiation, Front. Plant Sci. 6 (2015) 1028, https://doi.org/10.3389/ fpls.2015.01028.

[60] C. Yamamuro, J.-K. Zhu, Z. Yang, Epigenetic modifications and plant hormone action, Mol. Plant 9 (2016) 57-70.

[61] I.R. Henderson, S.E. Jacobsen, Tandem repeats upstream of the Arabidopsis endogene $S D C$ recruit non-CG DNA methylation and initiate siRNA spreading, Genes Dev. 22 (2008) 1597-1606, https://doi.org/10.1101/gad.1667808.

[62] L. Bruno, M. Ronchini, O. Gagliardi, T. Corinti, A. Chiappetta, P. Gerola, M.B. Bitonti, Analysis of AtGUS1 and AtGUS2 in Arabidopsis root apex by a highly sensitive TSA-MISH method, Int. J. Dev. Biol. 59 (2015) 221-228, https://doi.org/ 10.1387/ijdb.140195LB.

[63] T. Murashige, F. Skoog, A revised medium for rapid growth and bioassays with tobacco tissue cultures, Physiol. Plant. 15 (1962) 473-497.

[64] M. Karampelias, P. Neyt, S. De Groeve, S. Aesaert, G. Coussens, J. Rolčík, L. Bruno, N. De Winne, A. Van Minnebruggen, M. Van Montagu, M.R. Ponce, J.L. Micol, J. Friml, De G. Jaeger, M. Van Lijsebettens, ROTUNDA3 function in plant development by phosphatase 2A-mediated regulation of auxin transporter recycling, Proc. Natl. Acad. Sci. U. S. A. 113 (2016) 2768-2773, https://doi.org/10.1073/ pnas.1501343112.

[65] L. Bruno, M. Pacenza, I. Forgione, L. R-Lamerton, M. Greco, A. Chiappetta, M.B. Bitonti, In Arabidopsis thaliana cadmium impact on the growth of primary root by altering SCR expression and auxin-cytokinin cross-talk, Front. Plant Sci. 8 (2017) 1323, https://doi.org/10.3389/fpls.2017.01323.

[66] R. Dello Ioio, F.S. Linhares, E. Scacchi, E. Casamitjana-Martinez, R. Heidstra, P. Costantino, S. Sabatini, Cytokinins determine Arabidopsis root-meristem size by controlling cell differentiation, Curr. Biol. 17 (2007) 678-682, https://doi.org/10. 1016/j.cub.2007.02.047.

[67] A. Grabov, M.K. Ashley, S. Rigas, P. Hatzopoulos, L. Dolan, F. Vicente-Agullo, Morphometric analysis of root shape, New Phytol. 165 (2005) 641-651, https: / doi.org/10.1111/j.1469-8137.2004.01258.x.

[68] G. Cnops, S. Jover-Gil, J.L. Peters, P. Neyt, S. De Block, P. Robles, M.R. Ponce, T. Gerats, J.L. Micol, M.Van Lijsebettens, The rotunda2 mutants identify a role for the LEUNIG gene in vegetative leaf morphogenesis, J. Exp. Bot. 55 (2004) 1529-1539.

[69] E. Benková, M. Michniewicz, M. Sauer, T. Teichmann, D. Seifertová, G. Jürgens, J. Friml, Local, efflux-dependent auxin gradients as a common module for plant organ formation, Cell 115 (2003) 591-602.

[70] I. Blilou, J. Xu, M. Wildwater, V. Willemsen, I. Paponov, J. Friml, R. Heidstra, M. Aida, K. Palme, B. Scheres, The PIN auxin efflux facilitator network controls growth and patterning in Arabidopsis roots, Nature 433 (2005) 39-44.

[71] S.G. Villas-Bôas, D.G. Delicado, M. Åkesson, J. Nielsen, Simultaneous analysis of amino and non amino organic acids as methyl chloroformate derivatives using gas chromatography-mass spectrometry, Anal. Biochem. 322 (2003) 134-138.

[72] C. Rawlinson, L.G. Kamphuis, J.P. Gummer, K.B. Singh, R.D. Trengove, A rapid method for profiling of volatile and semi-volatile phytohormones using methyl chloroformate derivatisation and GC-MS, Metabolomics 11 (2015) 1922-1933.

[73] J. Hellemans, G. Mortier, A. De Paepe, F. Speleman, J. Vandesompele, qBase relative quantification framework and software for management and automated analysis of real-time quantitative PCR data, Genome Biol. 8 (2007) R19, https:// doi.org/10.1186/gb-2007-8-2-r19.

[74] M. Weber, D. Schoubeler, Methylated DNA Immunoprecipitation (MeDIP), (2007) PROT33.

[75] E. Casamitjana-Martínez, H.F. Hofhuis, J. Xu, C.M. Liu, R. Heidstra, B. Scheres, Root-specific CLE19 overexpression and the sol1/2 suppressors implicate a CLV-like pathway in the control of Arabidopsis root meristem maintenance, Curr. Biol. 13 (2003) 1435-1441, https://doi.org/10.1016/S0960-9822(03)00533-5.

[76] E.M. Sato, H. Hijazi, M.J. Bennett, K. Vissenberg, R. Swarup, New insights into root gravitropic signalling, J. Exp. Bot. 66 (2015) 2155-2165, https://doi.org/10.1093/ jxb/eru515.

[77] A. Müller, C. Guan, L. Gälweiler, P. Tänzler, P. Huijser, A. Marchant, AtPIN2 defines a locus of Arabidopsis for root gravitropism control, EMBO J. 17 (1998) 6903-6911, https://doi.org/10.1093/emboj/17.23.6903.

[78] R. Swarup, J. Friml, A. Marchant, K. Ljung, G. Sandberg, K. Palme, M. Bennett, Localization of the auxin permease AUX1 suggests two functionally distinct hormone transport pathways operate in the Arabidopsis root apex, Genes Dev. 15 (2001) 2648-2653, https://doi.org/10.1101/gad.210501.

[79] A. Trewavas, How do plant growth substances work? Plant Cell Environ. 4 (1981) 203-228.

[80] T.J. Donner, I. Sherr, E. Scarpella, Regulation of preprocambial cell state acquisition by auxin signaling in Arabidopsis leaves, Development 136 (2009) 3235-3246.

[81] P.J. Davies, The Plant Hormones: Their Nature, Occurrence, and Functions. Plant Hormones, Springer, Dordrecht, 2010.

[82] E. Zažímalová, J. Petrasek, E. Benková, Auxin and Its Role in Plant Development, Springer, Dordrecht, 2014.

[83] P.D. Jenik, M.K. Barton, Surge and destroy: the role of auxin in plant 
embryogenesis, Development 132 (2005) 3577-3585, https://doi.org/10.1242/ dev.01952.

[84] D.L. Yang, G. Zhang, K. Tang, J. Li, L. Yang, H. Huang, H. Zhang, J.K. Zhu, Dicerindependent RNA-directed DNA methylation in Arabidopsis, Cell Res. 26 (2016) 1264, https://doi.org/10.1038/cr.2016.122.

[85] R. Chen, C. Guan, K. Boonsirichai, P.H. Masson, Complex physiological and molecular processes underlying root gravitropism, Plant Mol. Biol. 49 (2002) 305-317.

[86] M. Bar, N. Ori, Leaf development and morphogenesis, Development 141 (2014)
4219-4230, https://doi.org/10.1242/dev.106195.

[87] K. Bainbridge, S. Guyomarc'h, E. Bayer, R. Swarup, M. Bennett, T. Mandel, C. Kuhlemeier, Auxin influx carriers stabilize phyllotactic patterning, Genes Dev. 22 (2008) 810-823, https://doi.org/10.1101/gad.462608.

[88] T. Bennett, T. Sieberer, B. Willett, J. Booker, C. Luschnig, O. Leyser, The Arabidopsi MAX pathway controls shoot branching by regulating auxin transport, Curr. Biol. 16 (2006) 553-563. 